This item was submitted to Loughborough's Research Repository by the author.

Items in Figshare are protected by copyright, with all rights reserved, unless otherwise indicated.

\title{
Monitoring buried pipe deformation using acoustic emission: quantification of attenuation
}

PLEASE CITE THE PUBLISHED VERSION

http://dx.doi.org/10.1080/19386362.2016.1227581

PUBLISHER

(C) Taylor and Francis

\section{VERSION}

AM (Accepted Manuscript)

\section{PUBLISHER STATEMENT}

This work is made available according to the conditions of the Creative Commons Attribution-NonCommercialNoDerivatives 4.0 International (CC BY-NC-ND 4.0) licence. Full details of this licence are available at: https://creativecommons.org/licenses/by-nc-nd/4.0/

\section{LICENCE}

CC BY-NC-ND 4.0

\section{REPOSITORY RECORD}

Smith, Alister, Neil Dixon, and Gary Fowmes. 2016. "Monitoring Buried Pipe Deformation Using Acoustic Emission: Quantification of Attenuation”. Loughborough University. https://hdl.handle.net/2134/22371. 


\section{Monitoring Buried Pipe Deformation Using Acoustic Emission: Quantification of Attenuation}

International Journal of Geotechnical Engineering

Author 1 and corresponding author:

Alister Smith, MEng(Hons), PhD, FGS

Research Fellow in Geotechnical Engineering, School of Civil and Building

Engineering, Loughborough University, Leicestershire, UK

Author 2:

Neil Dixon, BSc, PhD, FGS

Professor of Geotechnical Engineering, School of Civil and Building Engineering, Loughborough University, Leicestershire, UK

Author 3:

Gary Fowmes, BSc, MSc, EngD, CEng, MICE

Senior Lecturer in Engineering Geology, School of Civil and Building Engineering, Loughborough University, Leicestershire, UK 


\section{Monitoring Buried Pipe Deformation Using Acoustic Emission: Quantification of Attenuation}

Deformation of soil bodies and soil-structure systems generates acoustic emission (AE), which are high-frequency stress waves. Listening to this AE by coupling sensors to structural elements can provide information on asset condition and early warning of accelerating deformation behaviour. There is a need for experimentation to model the propagation of $\mathrm{AE}$ in buried pipe systems to enhance understanding of real behaviour. Analytical solutions are often based on many assumptions (e.g. homogeneity, isotropy, boundary conditions and material properties) and cannot exactly represent the behaviour of the in situ system. This paper details a series of experiments conducted on buried pipes to investigate $\mathrm{AE}$ attenuation in pipes due to couplings and soil surround. The attenuation coefficients reported provide guidance to engineers for designing sensor spacing along buried pipes for monitoring ground deformations, and active waveguide installation depths for slope deformation monitoring. Attenuation coefficients have been quantified for both air-pipe-air and air-pipe-soil tri-layer systems for the frequency range of 20 to $30 \mathrm{kHz}$.

Keywords: acoustic emission; attenuation; buried pipes; deformation; field instrumentation; landslides; monitoring; non-destructive testing; slopes

\section{Introduction}

Acoustic emission (AE) monitoring of slopes uses active waveguides (Figure 1), which are installed in boreholes, or retrofitted inside existing inclinometer or standpipe casings. They are installed to intersect existing or anticipated shear surfaces beneath the slope, and they comprise the composite system of a steel tube, connected in lengths using screw threaded couplings, with a granular backfill surround (i.e. a type of buried pipe). As the host slope deforms, the active waveguide deforms, and this causes particle-particle and particle-waveguide interactions to take place, which generate the AE. The predominant zone of AE generation is at the shear surface. Generated AE rates are proportional to applied displacement rates, where the coefficient of proportionality 
is dependent on the depth to the shear surface and the distance AE propagates along the waveguide to the ground surface where it is measured. Quantifying this magnitude of attenuation for each installation is essential to deriving slope displacement rates from measured $\mathrm{AE}$ rates, which can be used to warn users of accelerating slope deformation behaviour to enable evacuation of vulnerable people and timely repair and maintenance of critical infrastructure (Koerner et al., 1981; Nakajima et al., 1991; Smith et al., 2014a; Smith et al., 2014b; Dixon et al., 2015a; Dixon et al., 2015b; Smith, 2015; Smith \& Dixon, 2015; Smith et al., 2016).

\section{[Insert Figure 1 here]}

Developments in AE monitoring of pipe networks (e.g. Alleyne \& Cawley, 1992; Alleyne \& Cawley, 1997) for the detection and location of defects (e.g. Lowe et al., 1998) and leaks (e.g. Mostafapour \& Davoudi, 2013; Anastasopoulos et al., 2009) have led to a need for greater understanding of AE propagation in buried pipes. The UK alone is home to tens of thousands of kilometres of buried pipelines, both on shore and offshore, intersecting a variety of soils, transporting millions of tonnes of petroleum products (e.g. petrol, diesel, oil and gas), potable water, and waste. A significant length of these assets intersects potentially unstable ground. Ground movements cause high stresses and strains to develop within the pipe which eventually lead to damage and leakage. If AE generated by the deforming soil, and by deformations at the soil-pipe interface, propagating through the pipe can be monitored, it would be possible to detect and locate such ground movements so that targeted remediation can be performed. There is a need for experimentation to model the propagation of $\mathrm{AE}$ in buried pipe systems to enhance understanding of real behaviour. Analytical solutions are often based on many assumptions (e.g. homogeneity, isotropy, boundary conditions and material properties) and cannot exactly represent the behaviour of the in situ system. 
This paper details a series of experiments conducted on buried pipes to investigate AE attenuation due to couplings and soil surround. The objective of the study was to quantify attenuation coefficients that could provide guidance to engineers for designing sensor spacing along buried pipes for monitoring ground deformations, and active waveguide installation depths for slope deformation monitoring.

\section{Wave propagation in shell structures}

\section{Background}

Buried pipes can act as a preferential path for $\mathrm{AE}$ stress waves to propagate along the pipe, and hence through the ground, from the generation source to a monitoring location. The pipe can therefore be considered to act as a 'waveguide'. Exact analytical solutions exist for progressive simple harmonic waves of infinite duration propagating in uniform, isotropic, solid circular cylinders of infinite length; one such solution being the Pochhammer-Chree analysis. Gazis (1959) obtained a general solution of harmonic waves in a cylinder surrounded by a vacuum. Studies of wave propagation along submerged fluid filled pipes (e.g. Aristegui et al., 2001) and buried water pipes (e.g. Long et al., 2003a,b) have demonstrated that the dominant wave modes in each case are dependent on the frequency content of the source, the geometry and properties of the pipe, and the internal and external environments. Long et al., (2003a,b) detail an investigation of acoustic wave propagation in buried iron pipes and highlight that significant energy is lost into the surrounding soil if 'leaky' wave modes propagate (i.e. wave induced displacements occur on the outer surface of the pipe and are therefore damped by the surrounding media). The magnitude of wave attenuation is dependent on the propagating wave mode, and attenuation generally 
occurs due to; geometric spreading, leakage (e.g. losses at boundaries), material properties, and scattering at joints (Long et al., 2003a,b; Shehadeh et al., 2008).

Shehadeh et al., (2008) understood that waveguide pipes installed in the ground (e.g. active waveguides) have a combination of air and water (e.g. ground water) as an internal environment (i.e. inside the pipe), and soil (saturated, partially saturated or dry) as an external environment (i.e. outside the pipe); therefore forming air-waveguide-soil and water-waveguide-soil tri-layer systems. Buried pipes can also have waste or petroleum products as an internal environment. Shehadeh et al., (2008) monitored relatively high frequency (i.e. 100-200 kHz and 300-350 kHz) AE wave propagation in air-steel pipe-air systems and water-steel pipe-wet sand systems. The results demonstrate that the amplitude of the signal detected $5 \mathrm{~m}$ from the source in the watersteel pipe-wet sand system was an order of magnitude lower than in the equivalent airsteel pipe-air system. This highlights the potential for significant AE leakage to occur into the surrounding media when monitoring relatively high frequency signals. Long et al., (2003a,b) conducted experimentation on buried iron water pipes (i.e. water-iron pipe-soil tri-layer systems) and monitored in a low frequency range (i.e. $<5 \mathrm{kHz}$ ); they found that the signal propagated $175 \mathrm{~m}$ and the amplitude reduced by less than a half. Anastasopoulos et al., (2009) also found that sensor spacing of $100 \mathrm{~m}$ was sufficient to monitor low frequency AE propagation in buried metal pipes for leak detection purposes. These results highlight that the degree of attenuation experienced is significantly dependent on the frequency content of the stress waves, which also governs the wave modes that propagate.

\section{Wave modes}

The fundamental relationship between wavelength $(\lambda)$, frequency $(f)$ and velocity $(C)$ is given by: 


$$
\lambda=\frac{C}{f}
$$

Low-frequency stress waves in thin rods or tubes (where the wavelength ' $\lambda$ ' is much greater than the diameter ' $d$ ' and wall thickness ' $t$ ') propagate as plane longitudinal, flexural (i.e. shear or transverse) and torsional wave modes (Maji et al., 1997). The propagation velocity of plane longitudinal $\left(C_{l}\right)$ and shear $\left(C_{s}\right)$ wave modes are given respectively by (Maji et al., 1997):

$$
\begin{aligned}
C_{l} & =\sqrt{\frac{E}{\rho}} \\
C_{s} & =\sqrt{\frac{\mu}{\rho}}
\end{aligned}
$$

Where $\mathrm{E}=$ Young's modulus, $\mu=$ shear modulus of elasticity, and $\rho=$ material density.

High-frequency stress waves $(\lambda<<d, \lambda<<t)$ propagate as bulk longitudinal and shear waves inside the material and as Rayleigh waves on the surface. Relatively highfrequency waves propagating through a solid that is bounded by two surfaces (i.e. a plate or tube) where the thickness is of the order of a few wavelengths or less (i.e. $\lambda \sim t$ ) propagate as Lamb waves (symmetric-extensional and antisymmetric-flexural) (Beattie, 1983; Maji et al., 1997; Sikorska \& Pan, 2004).

Plane longitudinal waves in pipes induce cycles of positive and negative axial stress which, because of the Poisson effect, results in expansions and contractions. The propagation of plane longitudinal waves along a pipe is therefore influenced by the pipe's stiffness moduli, in addition to the material density and cross-sectional area. The propagation of plane flexural waves induces bending moments and shear forces and is therefore influenced by the pipe's flexural rigidity; in addition to the cross-sectional area, material density and stiffness moduli (Graff, 1975). 


\section{Attenuation coefficients}

Equation 4 details the formula used to derive the attenuation coefficient, $\alpha$, of a decaying plane wave.

$$
A=A_{0} e^{-\alpha x}
$$

Where $A$ represents the magnitude of the wave at some distance, $x$, from the source, and $A_{0}$ represents the magnitude of the signal at the source (i.e. un-attenuated). The term $e$ is Euler's (or Napier's) constant. This equation is used to represent the net effect of all forms of attenuation (e.g. geometrical spreading, internal friction, scattering, diffraction and dispersion) in this study. Rearrangement of Equation 4 to make the attenuation coefficient the subject yields:

$$
-\alpha=\left(\frac{1}{x}\right) \ln \left(\frac{A}{A_{0}}\right)
$$

The units of the attenuation coefficient output from Equation 5 are Nepers per metre $(\mathrm{Np} / \mathrm{m})$. Decibels per unit length are the units more commonly used; Nepers per metre can be converted to Decibels per metre $(\mathrm{dB} / \mathrm{m})$ by dividing by 0.1151 as shown in Equation 6.

$$
1 N_{p}=\frac{1}{20 \log _{10} e} d B \approx 0.1151 d B
$$

\section{Reflection and transmission}

Relative proportions of a wave propagating in a rod or pipe will be transmitted and reflected where there is a discontinuity in cross-section or material properties (Graff, 1975). The transmitted proportion of the wave at a boundary will undergo some form of mode conversion (Sikorska \& Pan, 2004) (e.g. waves transmitted into water will be converted to compressional waves as water has no shear strength and cannot accommodate shear waves). The relative proportions of reflected and transmitted waves at a boundary between two media (e.g. the pipe-soil interface) are dictated by their 
relative acoustic impedances $(Z)$ (e.g. Shiotani \& Ohtsu, 1999). The acoustic impedance and specific acoustic impedance (i.e. per unit area) of a material are shown in Equations 7 and 8 , respectively.

$$
Z_{t}=\rho C S \text { and } Z=\rho C
$$

Where $\rho$ is material density, $C$ is acoustic velocity and $S$ is cross-sectional area. At a boundary where there is a difference in acoustic impedance (e.g. at an interface between two materials or a discontinuity in cross-section), the fraction of the incident wave intensity that is reflected can be determined using Equation 9 (i.e. the reflection coefficient, $R_{c}$ ).

$$
R_{c}=\left(\frac{Z_{2}-Z_{1}}{Z_{2}+Z_{1}}\right)^{2}
$$

Where $Z_{2}$ refers to the material occupying the incident wave (e.g. the pipe) and $Z_{1}$ refers to the material into which the wave is transmitted (e.g. a coupling or surrounding soil). The term 'acoustic impedance' will be used for the specific acoustic impedance here, which has units $\mathrm{kg} / \mathrm{m}^{2} \mathrm{~s}$.

\section{Experimentation}

\section{Introduction}

Steel pipes are used in active waveguides because of their low attenuation characteristics (e.g. Koerner et al., 1981), and they form a significant percentage of buried pipelines. This study therefore focused on steel pipes. The geometry and properties of the steel tube used in this study are detailed in Table 1. Equations 1, 2 and 3 were used to determine the range of wavelengths, which when compared to the diameter/wall thickness of rods/pipes, satisfy the criteria for plane wave modes to propagate in steel waveguides. The shaded area in Figure 2 shows a 
range of values for which plane wave modes propagate in steel, and hence for which the results from this study are relevant.

\section{[Insert Table 1 here]}

[Insert Figure 2 here]

Experiments were performed on both air-pipe-air and air-pipe-soil tri-layer systems in order to quantify their attenuation coefficients. Attenuation in air-pipe-air trilayer systems were measured first, which provided a reference for comparison when examining attenuation in air-pipe-soil tri-layer systems. A schematic of the test setup for the first series of experiments can be seen in Figure 3, and a photograph of the test setup is shown in Figure 4.

\section{[Insert Figure 3 here]}

\section{[Insert Figure 4 here]}

A total of $5 \times 3.2 \mathrm{~m}$ lengths (plus an additional $0.5 \mathrm{~m}$ length) of the steel pipe were connected with screw threaded couplings. Screw threaded couplings were used as connections because they are used in active waveguides for slope stability monitoring. The pipe (total length of $16.5 \mathrm{~m}$ ) was placed on a series of sponges to elevate above the stable surface (i.e. table) and remove any mechanical contact and damp any interaction (as can be seen in Figure 4). Sponges were used because they have very low stiffness and density, and therefore the difference in acoustic impedance at the waveguidesponge interface was high and losses into the sponge were minimal. In addition, the sponge only covered $0.3 \%$ of the surface area of the pipe and therefore the losses into the sponge were assumed negligible by comparison to being surrounded by soil. The screw threaded couplings were hand tightened in the first experiment and subsequently tightened using chain wrenches and lubricated with silicone gel in the second (i.e. to improve connection and increase transmission). This allowed the influence of the 
quality of the joint on the transmission of the incident source waves to be investigated, and how this affects attenuation.

The second series of experiments aimed to investigate the influence of an external environment (i.e. soil) on the attenuation of AE propagating along the pipe. For this series of experiments a 14 m long trench was excavated: a schematic of the phases of the experiment can be seen in Figures 5a to 5d; and photographs of phases of filling in Figures 6a to 6c. Figure 5 also details the geometry of the trench experiments.

\section{[Insert Figure 5 here]}

[Insert Figure 6 here]

A total of $4 \times 3.2$ m lengths of the same pipe detailed in Table 1 were connected with screw threaded couplings (lubricated with silicone gel and tightened using chain wrenches), and lowered into the trench. Two soil types were used in this series of experiments; River Gravel (coarse grained soil with 4-12mm particle size range) and Clay (fine grained soil). The Clay used was the in situ soil, in which the trench was excavated. In both cases a base layer of the relevant material was placed and compacted on the bottom of the trench, onto which the pipe was placed before the trench was backfilled in sections; this ensured that the soil being tested was in contact with the entire circumference of the pipe. Figures $6 b$ and $6 c$ show photographs of the two soils backfilled over sections of the buried pipe. The River Gravel was dry and had a bulk density of $1510 \mathrm{~kg} / \mathrm{m} 3$, Table 2 details the properties of the Clay.

[Insert Table 2 here]

\section{AE measurement system}

A field-viable AE measurement system was used in this study. This system was used to ensure the results obtained are relevant to a range of field monitoring applications. The system is described as 'field-viable' because it includes functionality 
to remove low-frequency background noise (e.g. generated by construction activity and traffic) and it has low power requirements, which makes continuous monitoring for long durations in the field environment possible. A piezoelectric transducer was employed to convert the mechanical AE to an electrical signal. The transducer was a R3alpha (Physical Acoustics Corporation) with a $30 \mathrm{kHz}$ resonant frequency and this was selected to provide sensitivity over the monitored frequency range of 20 to $30 \mathrm{kHz}$. The transducer is coupled to the outer wall of the pipe with a small layer of silicone gel, and held in position using the compressive contact provided by an elastic band. A band pass filter attenuated signals outside of the 20 to $30 \mathrm{kHz}$ range to eliminate low-frequency background noise $(<20 \mathrm{kHz})$ and to keep the monitored range consistent with that used in slope monitoring field trials using active waveguides (e.g. Smith et al., 2014a; Smith et al., 2014b; Dixon et al., 2015a; Dixon et al., 2015b; Smith, 2015). Amplification of $70 \mathrm{~dB}$ was used to improve the signal to noise ratio.

AE propagation is frequency dependent and therefore the results presented in this paper are of specific relevance to the frequency range of 20 to $30 \mathrm{kHz}$; however, the general trends in behaviour also inform plane wave modes propagating in pipes at other frequencies.

Sampling, reconstructing and processing high-frequency AE waveforms requires a high specification PC-based system, which is impractical for the continuous monitoring for long durations in the field environment. Therefore, the system used measures ring-down counts (RDC) to remove the need to record and process the entire waveform. RDC are the number of times the signal amplitude crosses a programmable threshold level within a predetermined time period (i.e. using a comparator). Figure 7 illustrates an example AE waveform which crosses the threshold level 3 times within 
the period. The attenuated signal has reduced amplitude and is not able to cross the threshold level, yielding zero RDC.

\section{[Insert Figure 7 here]}

The number of RDC recorded by the sensor, when the threshold level is constant, can be assumed proportional to the amplitude, duration and hence energy of the AE wave at that location. This principle was used throughout the experiment to determine the number of RDC detected at various locations along the pipe relative to the RDC detected at the location of the source. This empirical approach is appropriate for quantifying attenuation of soil-generated $\mathrm{AE}$ which is highly variable.

\section{AE source generator}

Figure 8 shows a series of waveforms recorded, using a MISTRAS Group USB $\mathrm{AE}$ node and the same $30 \mathrm{kHz}$ resonant frequency transducer as described in ' $A E$ measurement system', from granular soil deforming around the same steel pipe as in Table 1, using the same test apparatus as Smith \& Dixon (2015). This test apparatus was originally designed to model active waveguide behaviour. The typical soil-generated AE waveform was consistent with Figures $8 \mathrm{a}$ and $8 \mathrm{~b}$, and is generated by soil particleparticle and particle-pipe frictional interactions. The waveforms with significantly greater energy, by an order of magnitude, shown in Figures 8c and 8d occurred occasionally when slip-stick particle contact network rearrangement occurred (e.g. release of contact stress and stress redistribution as interlocking is overcome and regained).

\section{[Insert Figure 8 here]}

These waveforms demonstrate the variability in AE generated by deforming soil due to the various complex mechanisms that occur. Moreover, AE generated by deforming soil is continuous throughout the period of deformation, which could be 
hours or even days (e.g. Smith et al., 2014a). Because soil generated AE is highly variable and is continuous over long durations, it is not appropriate to attempt to replicate soil-generated $\mathrm{AE}$ with a single transient source. Continuous vibration over a set time period was therefore investigated as a generation mechanism to produce $\mathrm{AE}$ similar to that of particle-particle and particle-pipe interactions (e.g. to approximate/replicate the waveforms shown in Figures $8 \mathrm{a}$ and $8 b$ ).

A portable battery powered $\mathrm{AE}$ generation system was developed to produce consistent and repeatable $\mathrm{AE}$ in the field, comparable to soil-generated AE. A photograph of the AE source generator is shown in Figure 9.

[Insert Figure 9 here]

The source is a $26000 \mathrm{rpm}$ DC motor with a power input of $6 \mathrm{~V}$. The motor is encased in a water proof metal casing and is connected to the pipe using magnets. The motor is supplied power in 10 second bursts provided by a control box; when the 'on' button is triggered, power is supplied to the motor for a period of 10 seconds and subsequently power is automatically disconnected. This provided a consistent and repeatable source of $\mathrm{AE}$ using 10 second bursts of vibration. Figures 10a and 10b show typical waveforms recorded by this generation system, which are similar (in terms of amplitude, frequency, pattern etc.) to those generated by deforming soil around the pipe in Figures $8 \mathrm{a}$ and $8 \mathrm{~b}$. Calibration experiments have demonstrated that this source and operation produces repeatable numbers of RDC in the frequency range monitored. It was therefore reasonable to assume that the attenuation experienced by this AE source was representative of that experienced by deforming soil generated AE.

[Insert Figure 10 here] 


\section{Experimental procedure}

The experimental procedure employed in the testing of the air-pipe-air system is shown in Figures 3 and 4. The source generator was stationary at one end of the pipe. The sensor was coupled to the pipe at the locations shown in Figure 3. A minimum of 5 x 10 second bursts of the source generator were induced into the pipe while the sensor was coupled at each location.

The experimental procedure employed in the testing of the air-pipe-soil systems was similar to that adopted for the air-pipe-air systems. A bed of soil was placed at the bottom of the trench, the pipe was lowered onto the bed, and then the pipe was gradually backfilled in sections as detailed in Figures 5a to 5d. The pipe was subjected to a minimum of $5 \times 10$ second bursts of the source generator while the sensor was coupled at each location. In this series of tests two sensors were used; a running sensor (i.e. moved from one location to the next - positions of the running sensor relative to couplings and backfilled sections can be seen in Figures 5c and 5d) and an end sensor that remained in the same location at the end of the pipe. The running sensor was coupled to the pipe adjacent to the backfilled length. The backfilled sections of the trench had soil compacted to consistent conditions (i.e. bulk density) resulting in overburden pressures of $4.4 \mathrm{kPa}$ from the River Gravel and $5.5 \mathrm{kPa}$ from the Clay.

The entire experimental procedure for all tri-layer systems was repeated with two different voltage threshold levels set on the sensor. This was conducted to replicate the effects of source signals with different amplitude and energy content (i.e. amplitude relative to the threshold) in order to establish the consistency of the RDC value (i.e. signal amplitude and energy) vs. propagation distance relationship for each tri-layer system with respect to the magnitude of source emissions. Voltage threshold levels of $0.1 \mathrm{~V}$ and $0.25 \mathrm{~V}$ were used. 


\section{Results}

\section{Air-pipe-air and air-pipe-soil tri-layer systems}

The results produced from the air-pipe-air tri-layer system tests can be seen in Figures $11 \mathrm{a}$ and $11 \mathrm{~b}$, which show the results from the pipe connected with loose couplings and tight couplings, respectively. The quality of the coupling significantly affects the transmission of the incident wave; the signal significantly attenuated in the pipe with loose couplings after $10 \mathrm{~m}$, whereas the pipe with tight couplings did not result in any significant attenuation after the full distance of $16.5 \mathrm{~m}$. On occasion the RDC detected at the entrance to a coupling was greater than RDC detected at the exit of a coupling; this is assumed to be due to the sensor detecting reflections from the joint in addition to the incident wave.

\section{[Insert Figure 11 here]}

Figure 12 shows the percentage signal loss over each coupling for the series of tests conducted on air-pipe-air tri-layer systems. The percentage loss was determined from the difference between the average RDC detected in the $3.2 \mathrm{~m}$ length of pipe preceding the coupling and the average RDC detected in the $3.2 \mathrm{~m}$ length of pipe succeeding the coupling. The signal losses over the couplings were significantly greater for the loose couplings. The average losses over joints in the systems with loose couplings and tight couplings were $76.1 \%$ and $9.2 \%$, respectively. A negative percentage loss (i.e. an increase) was recorded over the fourth coupling in the results from the tight couplings at $0.25 \mathrm{~V}$, which is hypothesised to be due to significant reflections from the end of the pipe.

\section{[Insert Figure 12 here]}

Hardy Jr, (1992) experimentally determined the percentage loss of signal amplitude over perpendicularly jointed lengths of rock bolts, using a variety of 
connection methods (e.g. welding, soldering and clamping); the results demonstrated that welding was the most effective method of connection from those tested with an average signal amplitude loss of $22 \%$. When welding is used as a method to connect lengths of pipe, as is typically the case to connect lengths of metal pipe in buried pipelines to convey water, waste and petroleum products, the cross-section, and therefore the acoustic impedance, at the joint would remain relatively constant; resulting in reduced reflection and greater transmission. Losses at joints are therefore expected to be less when lengths are connected using welds as opposed to using screw threaded couplings. Discontinuities in cross-section are also present if the pipe is corroded, increasing the magnitude of losses.

The results produced from the air-pipe-River Gravel and air-pipe-Clay tri-layer systems can be seen in Figure 13. Figures $13 \mathrm{a}$ and $13 \mathrm{~b}$ show the results measured by the sensor coupled to the end of the pipe (i.e. the furthest distance from the source) while lengths of the pipe were gradually backfilled. Figures $13 \mathrm{c}$ and $13 \mathrm{~d}$ show the measured results obtained from the running sensor positioned adjacent to the backfilled lengths as the pipe was progressively covered.

\section{[Insert Figure 13 here]}

The general trend of RDC detected by the sensors in both the air-pipe-air and air-pipe-soil tri-layer systems decays linearly proportionally with propagation distance over the pipe length investigated; a linear regression was therefore plotted through the measured data points. The gradient of each of the linear regression lines fitted through the measured data sets gives an approximation for the attenuation coefficients (i.e. reduction in RDC per metre). The gradient of the RDC vs. propagation distance is comparable for both $0.1 \mathrm{~V}$ and $0.25 \mathrm{~V}$ threshold levels, indicating that the attenuation coefficient is independent of source magnitude. 
The results demonstrate that the River Gravel cover allowed propagation of the stress waves over $10 \mathrm{~m}$ at the lowest threshold level (i.e. highest source amplitude), whereas cover by the Clay resulted in severe damping of the signal to below the detection threshold by propagation of less than $4 \mathrm{~m}$ from the source.

The results detected from the running sensor were more variable than those detected by the end sensor; this is assumed to be due to greater or lesser magnitudes of reflections being detected by the running sensor dependent on its location in relation to a coupling. The end sensor detected greater magnitudes of RDC in each experiment than the running sensor, possibly due to AE reflecting from the free end of the pipe. This is particularly evident by the difference in RDC vs. distance relationships for the $0.1 \mathrm{~V}$ threshold experiments in Figures 13a and 13c; RDC ceased to be detected by the running sensor after reaching $9 \mathrm{~m}$, whereas RDC continued to be detected by the end sensor after $12 \mathrm{~m}$ of cover from River Gravel.

\section{Attenuation coefficients}

The attenuation coefficients were grouped for each tri-layer system (i.e. system total losses due to a combined effect of screw threaded couplings and internal/external environments) and are plotted in Figure 14. Coefficients determined from both voltage thresholds (i.e. $0.1 \mathrm{~V}$ and $0.25 \mathrm{~V}$ ) and from both sensor positions (i.e. running and end) show good agreement. The coefficients shown in Figure 14 confirm that the greatest attenuation occurred in the air-pipe-Clay tri-layer system while the least attenuation occurred in the air-pipe-air system with greased and tightened (i.e. high quality) couplings.

\section{[Insert Figure 14 here]}

Equations 4, 5 and 6 detail how the attenuation coefficients can be determined in decibels per metre using the ratio of the attenuated and original signal magnitude, and 
the distance of propagation between them. It is possible to use the ratio of RDC detected some distance from the source and adjacent to the source as values to input into the Equations. It is an appropriate assumption that the RDC values generated in this study are proportional to the magnitude of the signal, and therefore the ratio of RDC detected some distance from the source and adjacent to the source will yield an approximate value for the ratio of the attenuated and original signal magnitude. The attenuation coefficients determined for the tri-layer systems (including losses due to couplings) are shown in Table 3.

\section{[Insert Table 3 here]}

Shehadeh et al., (2008) quantified the attenuation coefficient for AE propagating in $48 \mathrm{~mm}$ outside diameter and $7.4 \mathrm{~mm}$ wall thickness steel pipes in the frequency range of 100 to $200 \mathrm{kHz}$; according to Figure 2, plane modes propagate in this case. An attenuation coefficient of $0.014 \mathrm{~Np} / \mathrm{m}$ (or $0.12 \mathrm{~dB} / \mathrm{m}$ ) was determined. The coefficient determined here for the air-pipe-air system with tight couplings was $0.02 \mathrm{~Np} / \mathrm{m}$ (or 0.16 $\mathrm{dB} / \mathrm{m}$ ), which is in close agreement with Shehadeh et al., (2008). The results were expected to be in close agreement because plane modes propagate in both cases. The coefficient in Shehadeh et al., (2008) is lower because solid lengths of pipe were examined with no couplings. The wavelength/wall thickness ratio also influences the attenuation; this ratio was less for the coefficient determined by Shehadeh et al., (2008) than for that determined here.

The percentage of source magnitude vs. propagation distance relationships have been determined using Equation 4 and the attenuation coefficients for the tri-layer systems (shown in Figure 15). The air-pipe-River Gravel system is the most representative of commonly used active waveguide systems (i.e. granular soil) for slope deformation monitoring, and was therefore of particular interest in this study. The 
results in Figure 15 suggest that monitoring slopes with shear surfaces tens of metres deep may be possible if the source AE generated at the shear surface is of sufficient magnitude (e.g. soil contact network rearrangement, which generates an order of magnitude greater AE than was investigated here, as shown in Figures 8 and 10).

[Insert Figure 15 here]

\section{Discussion of the influence of internal and external environments on the magnitude of $\mathrm{AE}$ attenuation in pipes}

Table 4 details the acoustic velocity, acoustic impedance and reflection coefficient (at the pipe-media interface) for the media involved in this study. A range of acoustic velocity values representative of the soils under study (e.g. representative sample depth, particle size distribution, moisture content, degree of compaction and density) were taken from Oelze et al., (2002) (mean and standard deviation of the values used are shown in Table 4), and the acoustic impedance of the soils was calculated using Equation 8 and their bulk density values.

\section{[Insert Table 4 here]}

The acoustic velocity and acoustic impedance of steel was determined using Equations 2 and 8 with values for parameters taken from Table 1. The acoustic velocity and acoustic impedance values used for water and air are standard. These values were input to Equation 9 to determine reflection coefficients at the pipe-external media interface for the media in Table 4. Figure 16 illustrates how the reflection coefficient at the pipe-external media interface varies with the acoustic impedance of the external media.

[Insert Figure 16 here]

Clay, River Gravel and air were the external media studied and their reflection coefficient vs. acoustic impedance relationship can be seen in Figure 16. The 
relationship was also determined for water to demonstrate the magnitude of reflection/ transmission at a pipe-water boundary, which is of interest as both the inside of an active waveguide pipe and the granular soil surround would contain water below the water table. In addition, soil surrounding buried pipes could contain water, whether saturated or partially saturated.

The reflection coefficient varies inversely proportionally to the acoustic impedance of the external media. As the acoustic impedance approaches the same value of the pipe (i.e. steel) the reflection coefficient becomes zero and the full magnitude of the wave entering the boundary will be transmitted. As the acoustic impedance approaches zero (e.g. air) the reflection coefficient approaches 1.0 (i.e. $100 \%$ reflection). These results show that as the acoustic impedance of the soil at the pipe-soil boundary increases (e.g. through increased density and/or stiffness moduli of the soil) the reflection coefficient at the interface would reduce, resulting in greater transmission (or signal loss) into the surrounding soil. Various scenarios in which the stiffness moduli and/or density of the surrounding soil will increase are described in Figure 17.

\section{[Insert Figure 17 here]}

Such scenarios are related to: the stress state of the surrounding soil (i.e. soil density and stiffness increases proportionally with depth, and hence with effective stress); the moisture content of the soil (i.e. location relative to the water table); and soil grading and packing.

Figure 17 demonstrates that the air-pipe-air and air-pipe-soil tri-layer system attenuation coefficients vary inversely proportionally to the reflection coefficient at the pipe-external media interface. There are a variety of scenarios that would result in an increased attenuation coefficient for the tri-layer systems studied while the reflection coefficient at the pipe-external media interface remained the same: if the quality of the 
couplings were reduced as demonstrated by the difference between 'tight' and 'loose' couplings in Figure 17 (the opposite is also true where the attenuation could be reduced by increasing the quality of the couplings through welding); or if the inside of the pipe was filled with media that altered the reflection coefficient at the pipe-internal media interface (e.g. when filled with water) as this will result in increased transmission (or loss) of AE into the internal media.

When an $\mathrm{AE}$ wave is transmitted into the internal media (e.g. fluid) at the pipeinternal media interface, the wave subsequently propagates through the fluid and some proportion (dictated by the reflection coefficient at the boundary) will then be transmitted back into the pipe. The AE wave will undergo mode conversions as it is transmitted from one media to another, for example; if the internal media within the pipe is water then the waves transmitted from the pipe into the water will be converted to compressional waves as water has no shear strength and cannot accommodate shear waves. The waves will subsequently be converted back into a combination of other modes (e.g. longitudinal, shear and torsional) as they are transmitted back into the pipe.

It is reasonable to assume that boundary losses in the air-pipe-air tri-layer system (i.e. losses into the surrounding air) are negligible and attenuation in this system is predominantly due to the material itself (i.e. steel) and losses at screw threaded couplings. Therefore, by subtracting the attenuation coefficients determined for the airpipe-air (tight couplings) tri-layer system from the air-pipe-soil tri-layer systems, both of which had the same quality couplings, values that represent boundary losses can be determined per metre of soil cover due to transmission of AE from the pipe into the soil (i.e. soil cover losses). These boundary loss attenuation coefficients due to soil cover were used in conjunction with Equation 4 to determine the percentage of source 
magnitude vs. propagation distance relationships for the two soil types examined (Figure 18).

\section{[Insert Figure 18 here]}

As stated earlier in this section, changes in soil acoustic impedance (e.g. through changed density and/or stiffness moduli) will result in greater/lesser losses due to an altered reflection coefficient at the pipe-soil interface. The soil cover losses presented in Figure 18 are for plane waves modes propagating in steel pipes/rods; if the material of the rod/pipe is changed then the reflection coefficient at the pipe-media interface will also change resulting in greater/lesser attenuation.

These results confirm that for the tri-layer systems studied, the coefficient of reflection at the internal/external interfaces significantly impacts on the propagation of $\mathrm{AE}$ (plane waves modes) along the pipe. An increased acoustic impedance of the internal/external media will result in a reduced reflection coefficient and therefore an increased attenuation coefficient for the internal media-steel pipe-external media trilayer system.

\section{Conclusions and future work}

This paper investigated attenuation of AE propagating in buried pipes, which is relevant to: early warning systems for slope instability that use active waveguides installed in boreholes; and non-destructive monitoring to detect and locate deterioration in buried pipes (e.g. pipes used to convey water, waste and petroleum products) due to deforming ground or failure of pipe/soil systems. The objective of the study was to quantify attenuation coefficients that could provide guidance to engineers for designing sensor spacing along buried pipes for monitoring ground deformations, and active 
waveguide installation depths for slope deformation monitoring. The principal findings are summarised in the following:

(a) Attenuation coefficients have been quantified for both air-pipe-air and airpipe-soil tri-layer systems for the frequency range of 20 to $30 \mathrm{kHz}: 0.16 \mathrm{~dB} / \mathrm{m}$ for air-pipe-air, $2.78 \mathrm{~dB} / \mathrm{m}$ for air-pipe-River Gravel and $4.75 \mathrm{~dB} / \mathrm{m}$ for airpipe-Clay;

(b) AE within 20 to $30 \mathrm{kHz}$ can propagate tens of metres along pipes buried in granular soil, and even greater distances when lengths are connected using welds, as opposed to screw threaded couplings, due to greater continuity in cross-section;

(c) Active waveguides could be used to monitor slopes with shear surfaces several, even tens, of metres deep;

(d) The frequency range monitored of 20 to $30 \mathrm{kHz}$ was selected to filter unwanted environmental noise; however, within this range AE in the air-pipefine grained soil system attenuated significantly after a few metres of propagation. Greater distances could be achieved by optimising the frequency range to monitor modes that are not 'leaky' (i.e. lose significant energy into surrounding media), and by monitoring lower frequency signals that suffer less attenuation (e.g. research has shown that AE can propagate hundreds of metres in buried pipes when monitoring at $<5 \mathrm{kHz}$ ). Monitoring lower frequency $\mathrm{AE}$ would be practical for monitoring buried pipe systems as the sensors could be buried below ground level, removing the need to filter out significant environmental noise. However, monitoring frequencies above $20 \mathrm{kHz}$ is important with active waveguides as the sensor is installed at the ground surface. 
Strategies to interpret the AE generated by deformation of soil bodies and soil-structure systems are required to enable users to make decisions based on information provided by the monitoring technique. Development of methodologies to interpret the AE is the next step in advancing the AE monitoring approach for this application.

\section{Acknowledgements}

The support provided by the Engineering and Physical Sciences Research Council (EP/H007261/1, EP/D035325) and Loughborough University is gratefully acknowledged. The authors also acknowledge the collaboration with Philip Meldrum, British Geological Survey, in development of the AE measurement system used in this study, and the excellent technical assistance provided by Mr Lewis Darwin.

\section{References}

Alleyne, D. N. \& Cawley, P. (1992). Optimization of Lamb Wave Inspection Techniques. NDT \& E International 25 (1): 11-22.

Alleyne, D. N. \& Cawley, P. (1997). Long Range Propagation of Lamb Waves in Chemcial Plant Pipework. Materials Evaluation 55 (4): 504-507.

Anastasopoulos, A., Kourousis, D. \& Bollas, K. (2009). Acoustic emission leak detection of liquid filled buried pipeline. Journal of Acoustic Emission, 27, 27-39.

Aristegui, C., Lowe, M. J. S. \& Cawley, P. (2001). Guided Waves in Fluid-Filled Pipes Surrounded by Different Fluids. Ultrasonics 39 (5): 367-375.

Beattie, A. G. (1983). Acoustic Emission, Principles and Instrumentation. Journal of Acoustic Emission 2 (1/2): 95-128. 
Dixon, N., Spriggs, M. P., Smith, A., Meldrum, P. \& Haslam, E. (2015a).

Quantification of reactivated landslide behaviour using acoustic emission monitoring. Landslides 12, No. 3, 549-560. DOI: 10.1007/s10346-014-0491-z.

Dixon, N., Smith, A., Spriggs, M. P., Ridley, A., Meldrum, P. \& Haslam, E. (2015b).

Stability monitoring of a rail slope using acoustic emission. Proceedings of the Institution of Civil Engineers - Geotechnical Engineering 168 (5), 373-384.

Gazis, D. C. (1959). Three-Dimensional Investigation of the Propagation of Waves in Hollow Circular Cylinders. I. Analytical Foundation. The Journal of the Acoustical Society of America 31 (5): 568-573.

Graff, K. F. (1975). Wave Motion in Elastic Solids. Courier Dover Publications.

Hardy Jr, H. R. (1992). Laboratory Studies Relative to the Development of Mechanical Waveguides for Acoustic Emission Monitoring of Geologic Structures. Italian Journal of Nondestructive Testing and Diagnostics 13 (2): 32-38.

Koerner, R. M., McCabe, W. M. \& Lord, A. E. (1981). Acoustic emission behaviour and monitoring of soils. In Acoustic Emission in Geotechnical Practice, ASTM STP 750, pp. 93-141.

Long R., Cawley, P. \& Lowe, M. J. S. (2003a). Acoustic Wave Propagation in Buried Iron Water Pipes. Proceedings of the Royal Society of London. Series A: Mathematical, Physical and Engineering Sciences 459 (2039): 2749-2770.

Long, R., Lowe, M. J. S. \& Cawley, P. (2003b). Attenuation Characteristics of the Fundamental Modes That Propagate in Buried Iron Water Pipes. Ultrasonics 41 (7): $509-519$.

Lowe, M. J. S., Alleyne, D. N. \& Cawley, P. (1998). Defect Detection in Pipes Using Guided Waves. Ultrasonics 36: 147-154. 
Maji, A. K., Satpathi, D. \& Kratochvil, T. (1997). Acoustic Emission Source Location Using Lamb Wave Modes. Journal of Engineering Mechanics 123: 154-161.

Mostafapour, A. \& Davoudi, S. (2013). Analysis of Leakage in High Pressure Pipe Using Acoustic Emission Method. Applied Acoustics 74 (3): 335-342.

Nakajima, I., Negishi, M., Ujihira, M. \& Tanabe, T. (1991). Application of the acoustic emission monitoring rod to landslide measurement. Proc. 5th Conf. on Acoustic Emission/Microseismic Activity in Geologic Structures and Materials, Pennsylvania, pp. $1-15$.

Oelze, M. L., O’Brien, W. D. \& Darmody, R. G. (2002). Measurement of Attenuation and Speed of Sound in Soils. Soil Science Society of America Journal 66 (3): 788796.

Shehadeh, M., Abdou, W., Steel, J. \& Reuben, R. (2008). Aspects of Acoustic Emission Attenuation in Steel Pipes Subject to Different Internal and External Environments. Proceedings of the Institution of Mechanical Engineers 222 (E): 42-54.

Shiotani, T. \& Ohtsu, M. (1999). Prediction of slope failure based on AE activity. In Acoustic Emission: Standards and Technology update (Vahaviolos, S.J. (Ed.)), American Society for Testing Materials, ASTM STP, Pennsylvania, 1353, pp. 157172.

Sikorska, J. \& Pan, J. (2004). The effect of waveguide material and shape on acoustic emission transmission characteristics. Journal of Acoustic Emission, 22, 264-273.

Smith, A. (2015). Quantification of slope deformation behaviour using acoustic emission monitoring. $\mathrm{PhD}$ thesis, Loughborough University. 
Smith, A. \& Dixon, N. (2015). Quantification of landslide velocity from active waveguide-generated acoustic emission. Canadian Geotechnical Journal 52, No. 4, 413-425. DOI: 10.1139/cgj-2014-0226.

Smith, A., Dixon, N., Meldrum, P., Haslam, E. \& Chambers, J. (2014a). Acoustic emission monitoring of a soil slope: Comparisons with continuous deformation measurements. Géotechnique Letters 4, No. 4, 255-261.

Smith, A., Dixon, N., Meldrum, P. \& Haslam, E. (2014b). Inclinometer casings retrofitted with acoustic real-time monitoring systems. Ground Engineering, October Issue.

Smith, A., Dixon, N. \& Fowmes, G. J. (2016). Early detection of first-time slope failures using acoustic emission measurements: large-scale physical modelling. Géotechnique. 


\section{Tables}

Table 1. Geometry and mechanical properties of steel steam pipe

\begin{tabular}{|c|c|c|c|c|c|c|c|c|c|}
\hline $\begin{array}{c}\text { Density } \\
\left(\mathbf{k g} / \mathbf{m}^{\mathbf{3}}\right)\end{array}$ & $\begin{array}{c}\text { Modulus } \\
\text { of } \\
\text { elasticity } \\
(\mathbf{P a})\end{array}$ & $\begin{array}{c}\text { Poisson's } \\
\text { ratio }\end{array}$ & $\begin{array}{c}\text { Shear } \\
\text { modulus } \\
(\mathbf{P a})\end{array}$ & $\begin{array}{c}\text { Outside } \\
\text { diameter } \\
(\mathbf{m m})\end{array}$ & $\begin{array}{c}\text { Wall } \\
\text { thickness } \\
(\mathbf{m m})\end{array}$ & $\begin{array}{c}\text { Internal } \\
\text { diameter } \\
(\mathbf{m m})\end{array}$ & $\begin{array}{c}\text { Cross } \\
\text { sectional } \\
\text { area } \\
\left(\mathbf{m}^{\mathbf{2}}\right)\end{array}$ & $\begin{array}{c}\text { Second } \\
\text { moment } \\
\text { of area } \\
\left(\mathbf{m}^{\mathbf{4}}\right)\end{array}$ & $\begin{array}{c}\text { Flexural } \\
\text { rigidity } \\
(\mathbf{E I})\left(\mathbf{N m} \mathbf{2}^{\mathbf{2}}\right)\end{array}$ \\
\hline & & & & & & & & & \\
7850 & $2.00 \mathrm{E}+11$ & 0.287 & $8.00 \mathrm{E}+10$ & 50 & 3 & 44 & 0.00044 & $1.228 \mathrm{E}-07$ & $2.46 \mathrm{E}+04$ \\
\hline
\end{tabular}

Table 2. Properties of the Clay used as soil cover

\begin{tabular}{|c|c|c|c|c|c|c|c|}
\hline $\begin{array}{c}\text { Moisture } \\
\text { content }(\%)\end{array}$ & $\begin{array}{c}\text { Bulk density } \\
\left(\mathrm{Mg} / \mathbf{m}^{3}\right)\end{array}$ & $\begin{array}{c}\text { Dry density } \\
\left(\mathbf{M g} / \mathbf{m}^{3}\right)\end{array}$ & $\begin{array}{c}\text { Particle } \\
\text { density } \\
\left(\mathrm{Mg} / \mathbf{m}^{3}\right) \\
\end{array}$ & Liquid limit (\%) & $\begin{array}{c}\text { Plastic } \\
\text { limit } \\
(\%)\end{array}$ & $\begin{array}{c}\text { Plasticity index } \\
(\%)\end{array}$ & $\begin{array}{c}\text { Liquidity } \\
\text { index }\end{array}$ \\
\hline 30.8 & 1.86 & 1.42 & 2.64 & 43.6 & 18.6 & 25 & 0.49 \\
\hline
\end{tabular}

Table 3. Attenuation coefficients determined for the systems tested (i.e. combined losses due to couplings and internal/external environments)

\begin{tabular}{|c|c|c|}
\hline \multirow[b]{2}{*}{ System } & \multicolumn{2}{|c|}{ Attenuation coefficient } \\
\hline & $(\mathrm{dB} / \mathrm{m})$ & $(\mathrm{Np} / \mathrm{m})$ \\
\hline Air-Pipe-Air (Tight couplings) & 0.16 & 0.02 \\
\hline Air-Pipe-Air (Loose couplings) & 2.03 & 0.23 \\
\hline Air-Pipe-River Gravel & 2.78 & 0.32 \\
\hline Air-Pipe-Clay & 4.75 & 0.55 \\
\hline
\end{tabular}

Table 4. Acoustic velocity, acoustic impedance and reflection coefficients (at the pipe-media interface) for media studied

\begin{tabular}{|c|c|c|c|c|c|c|}
\hline Media & \multicolumn{2}{|c|}{$\begin{array}{l}\text { Acoustic } \\
\text { velocity }(\mathrm{m} / \mathrm{s})\end{array}$} & \multicolumn{2}{|c|}{ Acoustic impedance $(Z)$} & \multicolumn{2}{|c|}{$\begin{array}{l}\text { Reflection coefficient }\left(\mathbf{R}_{c}\right) \\
\text { at pipe-media interface }\end{array}$} \\
\hline Steel & \multicolumn{2}{|l|}{5048} & \multicolumn{2}{|l|}{$3.96 \mathrm{E}+07$} & \multicolumn{2}{|l|}{0} \\
\hline Water & \multicolumn{2}{|l|}{1483} & \multicolumn{2}{|l|}{$1.48 \mathrm{E}+06$} & \multicolumn{2}{|l|}{0.861} \\
\hline \multirow[t]{2}{*}{ Air } & \multicolumn{2}{|l|}{332} & \multicolumn{2}{|l|}{$4.30 \mathrm{E}+02$} & \multicolumn{2}{|l|}{1} \\
\hline & Mean & $\begin{array}{l}\text { Standard } \\
\text { deviation } \\
\text { (ST } \\
\text { DEV) } \\
\end{array}$ & Mean & $\begin{array}{l}\text { Variability } \\
\text { (determined from } \\
\text { acoustic velocity ST } \\
\text { DEV) }\end{array}$ & Mean & $\begin{array}{l}\text { Variability } \\
\text { (determined from } \\
\text { acoustic velocity ST } \\
\text { DEV) }\end{array}$ \\
\hline $\begin{array}{l}\text { River } \\
\text { Gravel }\end{array}$ & 146 & 59 & $2.21 \mathrm{E}+05$ & $8.94 \mathrm{E}+04$ & 0.978 & 0.009 \\
\hline Clay & 168 & 60 & $3.12 \mathrm{E}+05$ & $1.11 \mathrm{E}+05$ & 0.969 & 0.011 \\
\hline
\end{tabular}




\section{Figures}

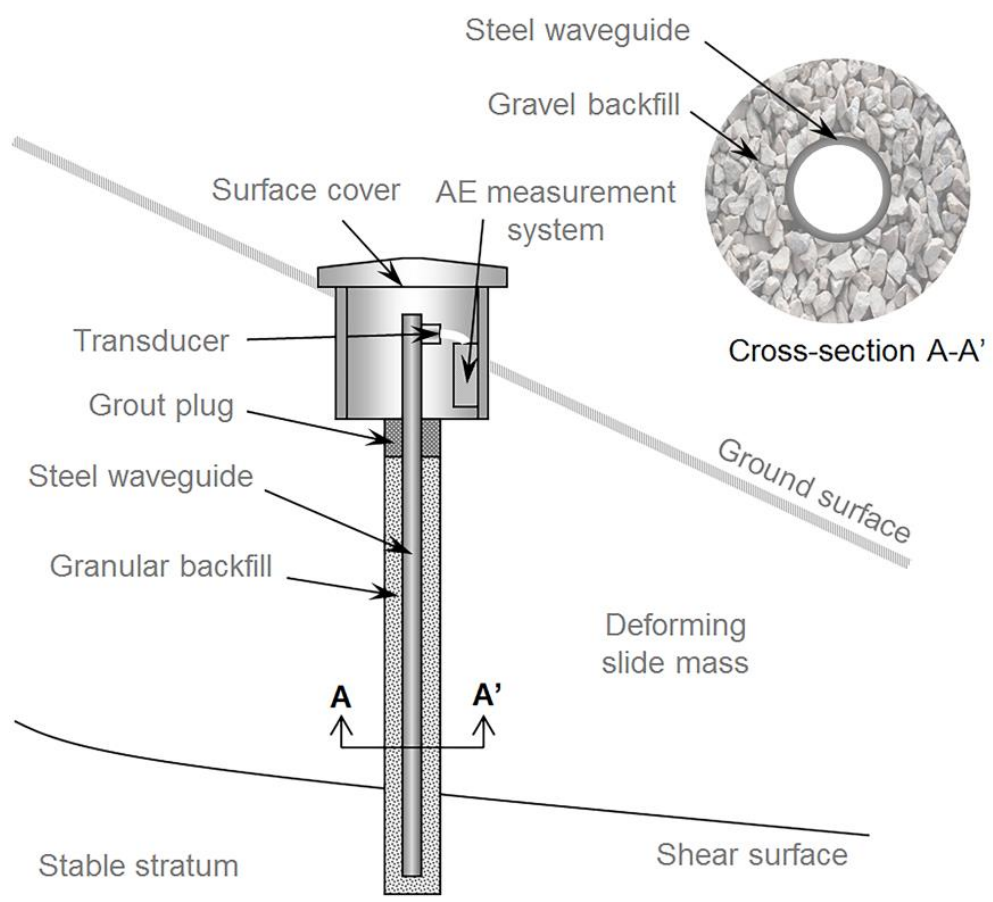

Figure 1. Schematic of the AE active waveguide slope stability monitoring system, modified after Smith et al., 2014a

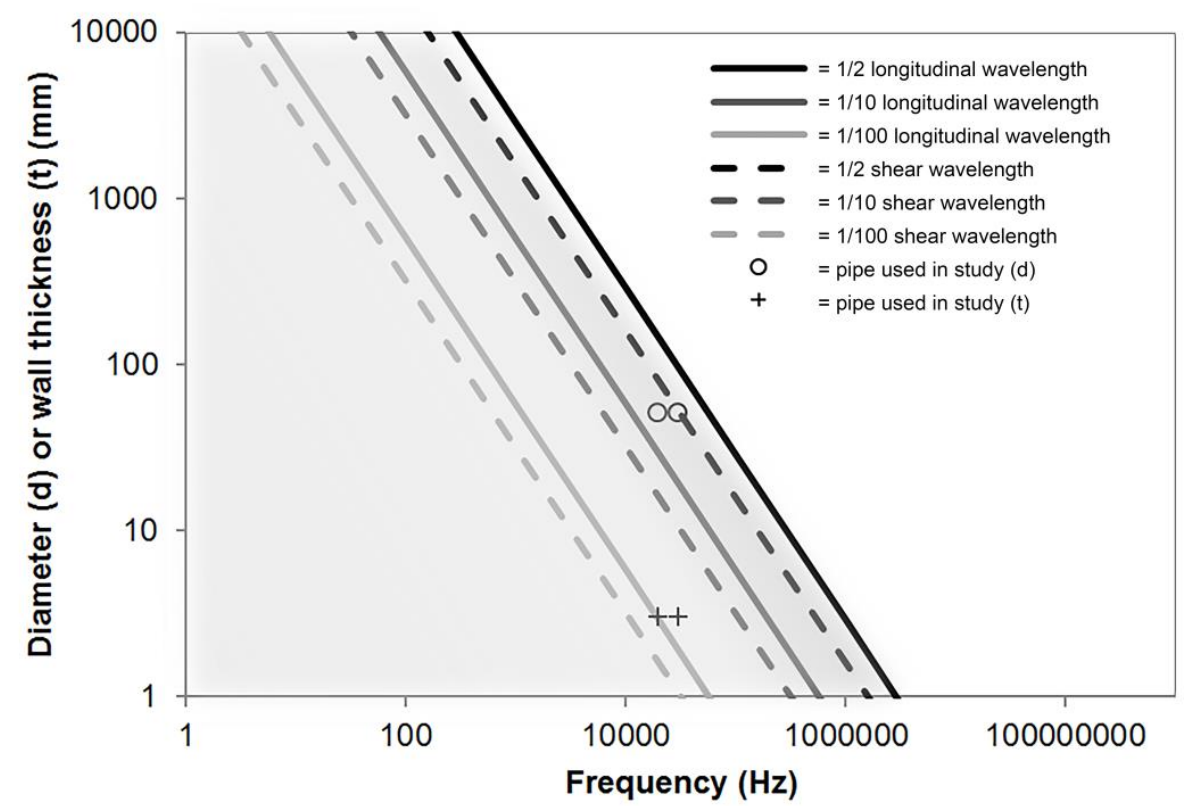

Figure 2. Example range of diameter, wall thickness and frequency values for which plane wave modes propagate in steel rods/pipes 


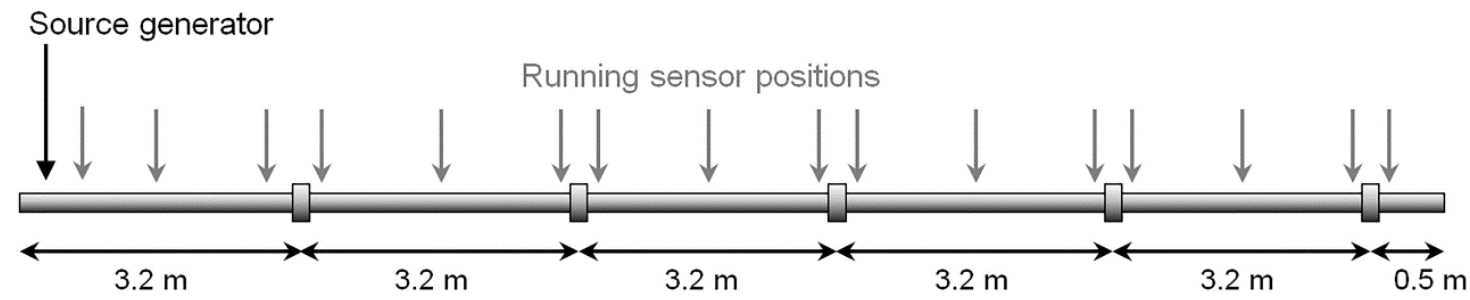

Figure 3. Air-pipe-air tri-layer system experiment: schematic of test setup with source generator and sensor positions highlighted

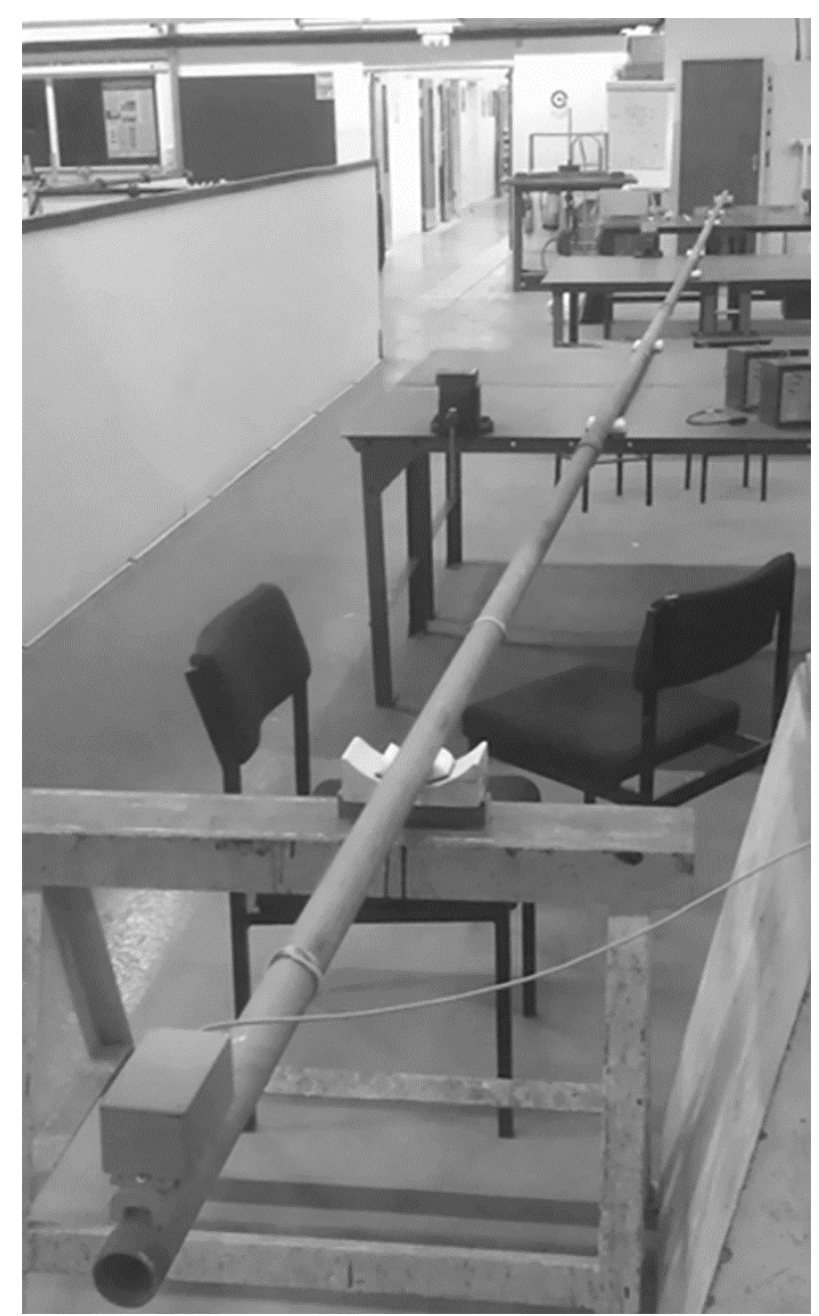

Figure 4. Photograph of the air-pipe-air tri-layer system experiment 


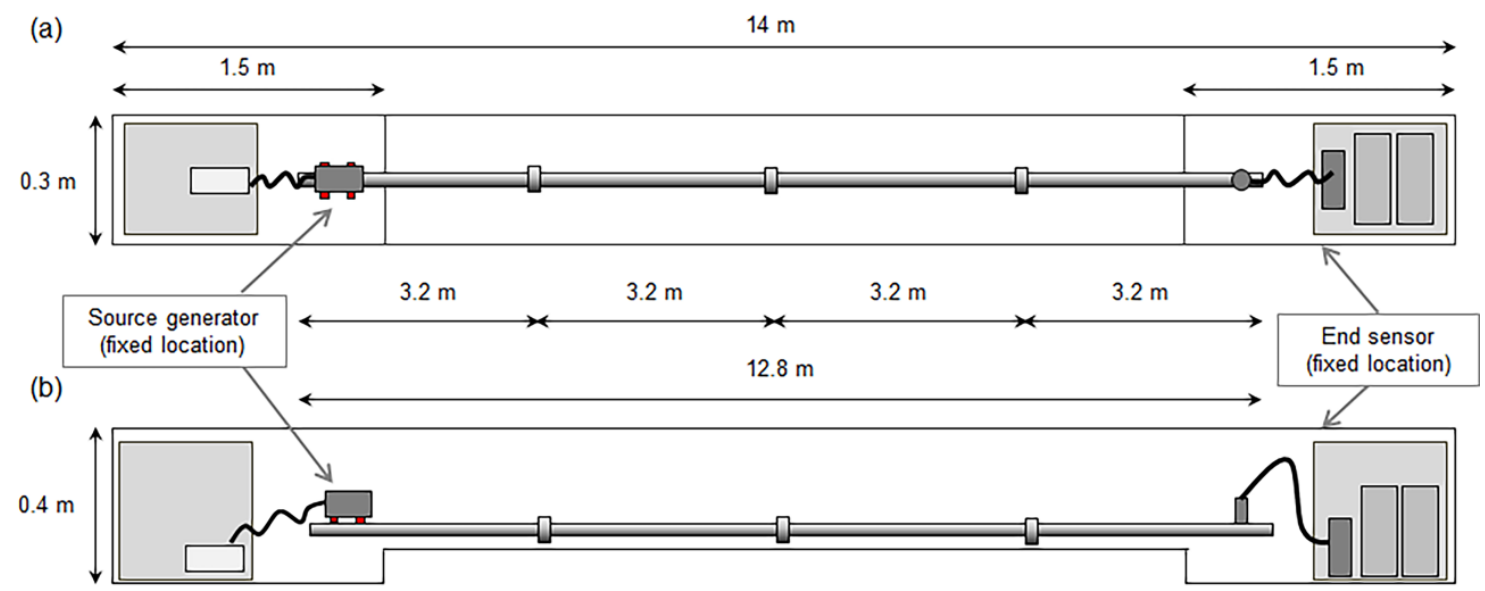

(c)

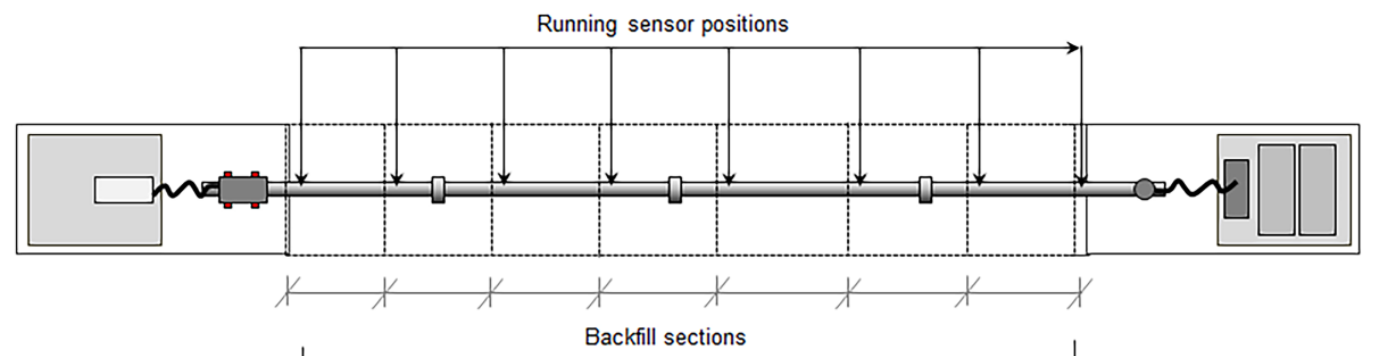

(d)

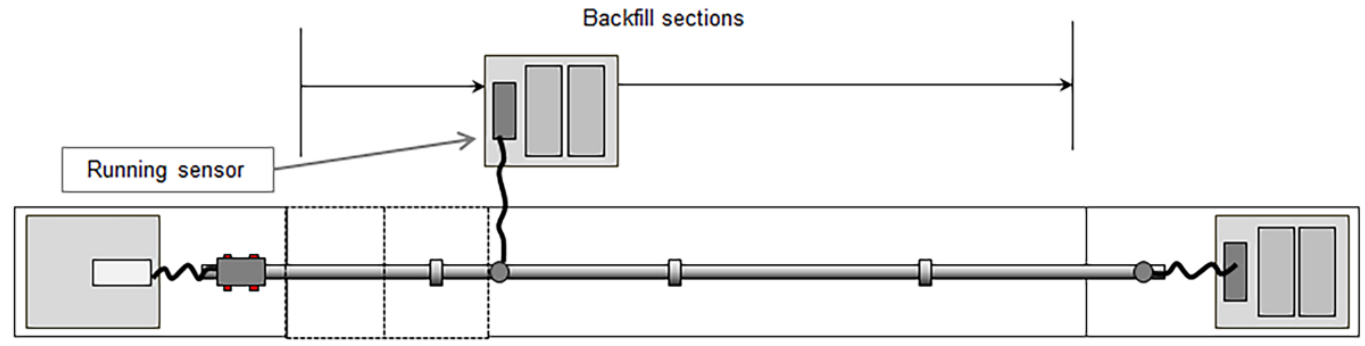

Figure 5. Schematic of air-pipe-soil tri-layer system experiments: a) plan and dimensions, b) elevation and dimensions, c) running sensor positions and backfill sections, d) running sensor at position \#3 with two sections backfilled
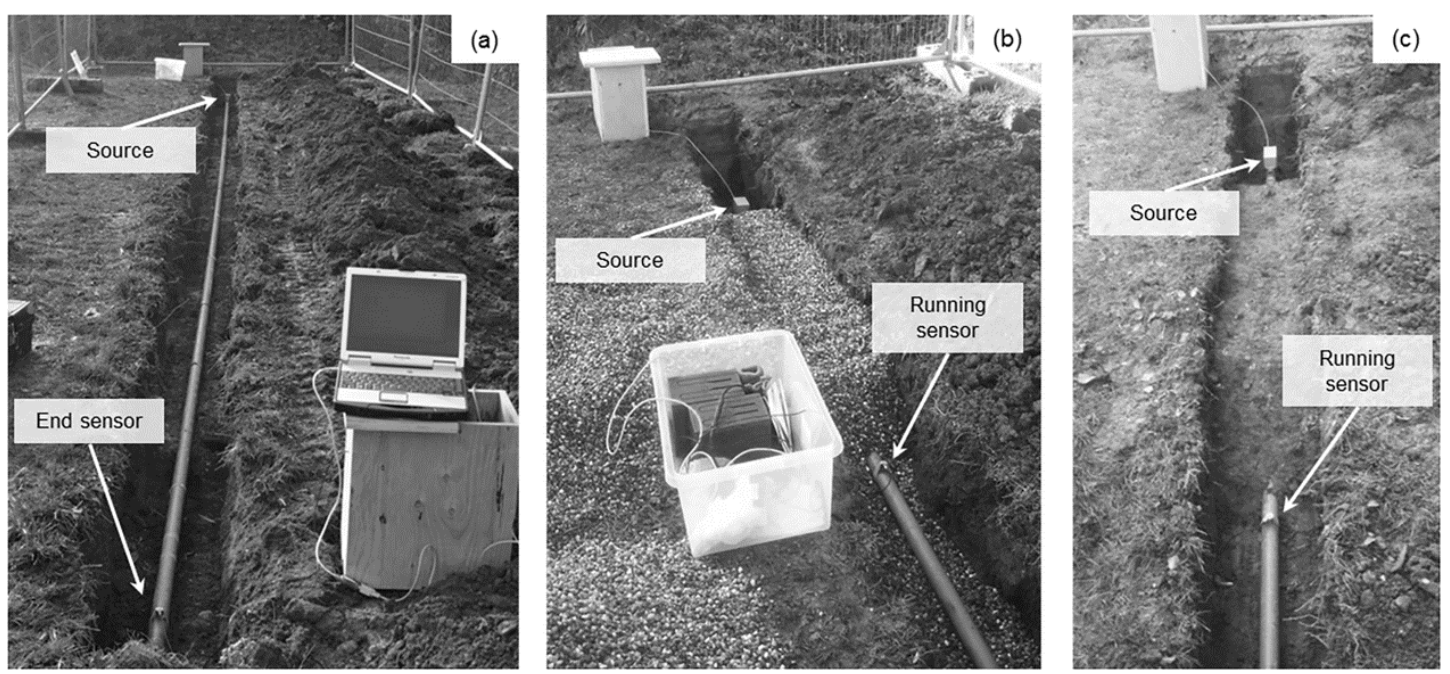

Figure 6. Photographs of the air-pipe-soil tri-layer system experiment: a) pipe placed at the base of the trench, b) pipe placed on River Gravel bed and backfilled with River Gravel, c) pipe placed on Clay bed and backfilled with Clay 


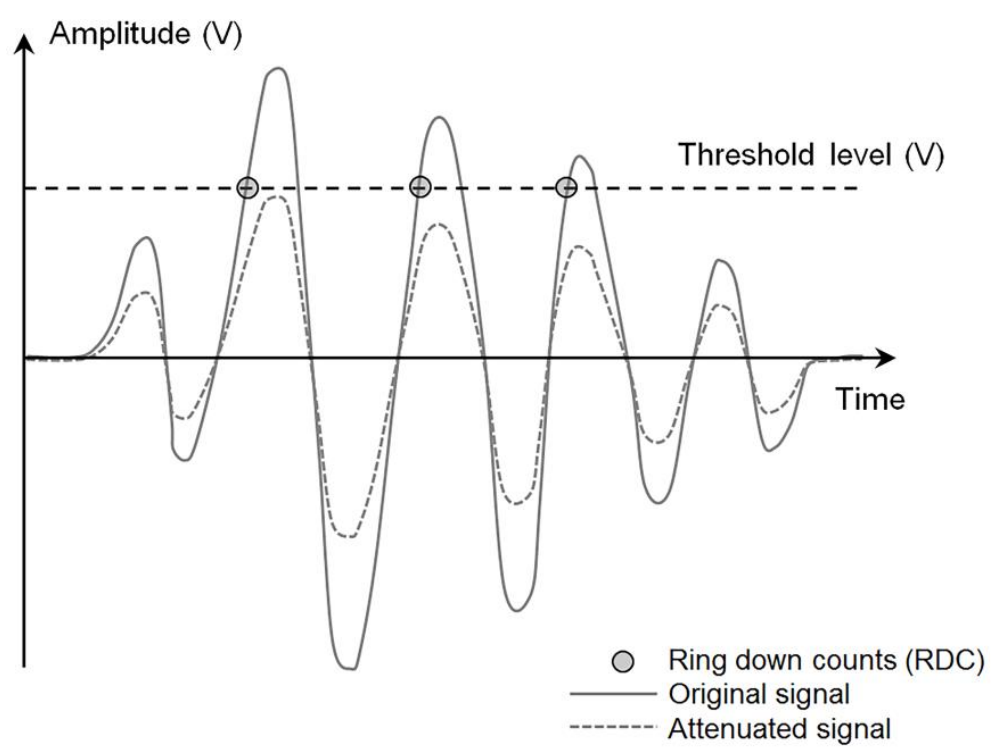

Figure 7. Simplified illustration of original and attenuated signals, voltage threshold level and ring-down counts
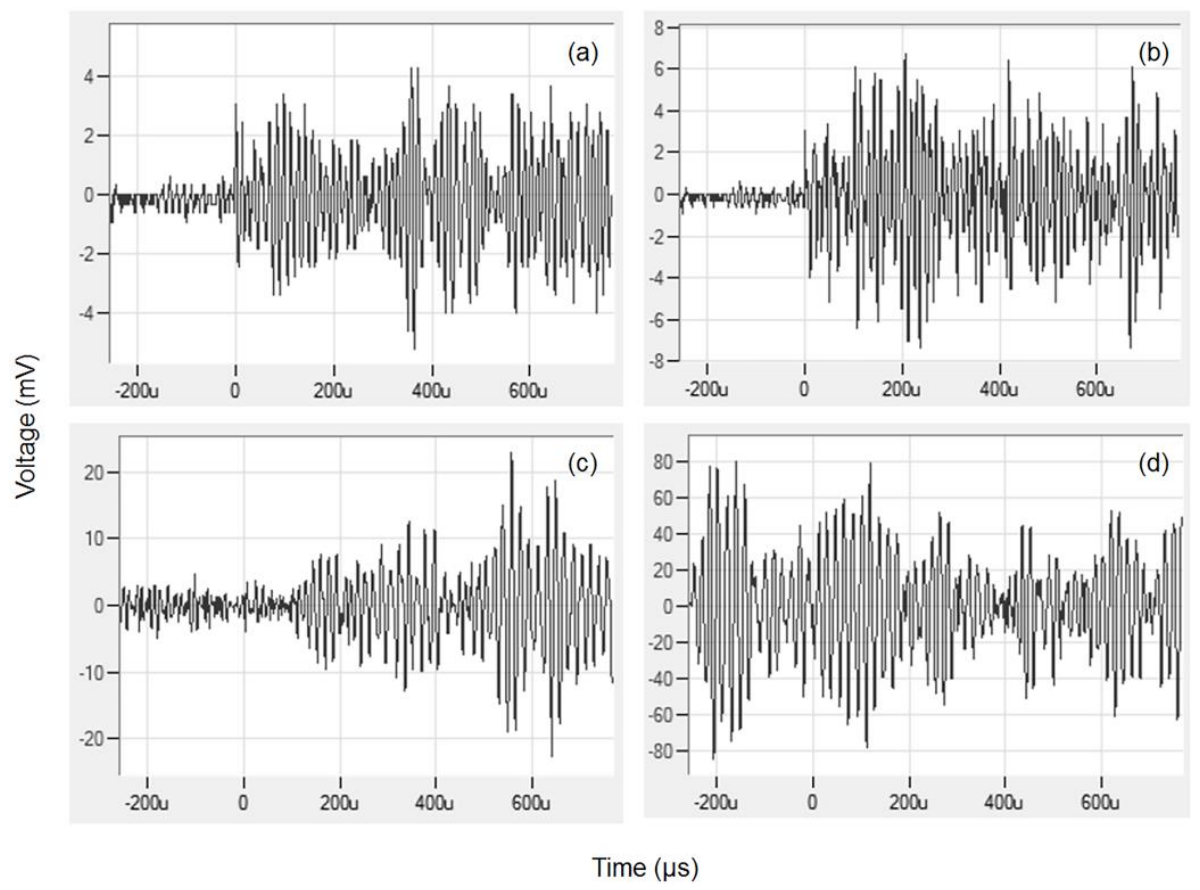

Figure 8. Sample AE waveforms generated by soil deforming around a pipe: a) and b) generated by particle-particle and particle-pipe interactions; and c) and d) generated by contact stress release and contact network rearrangement 


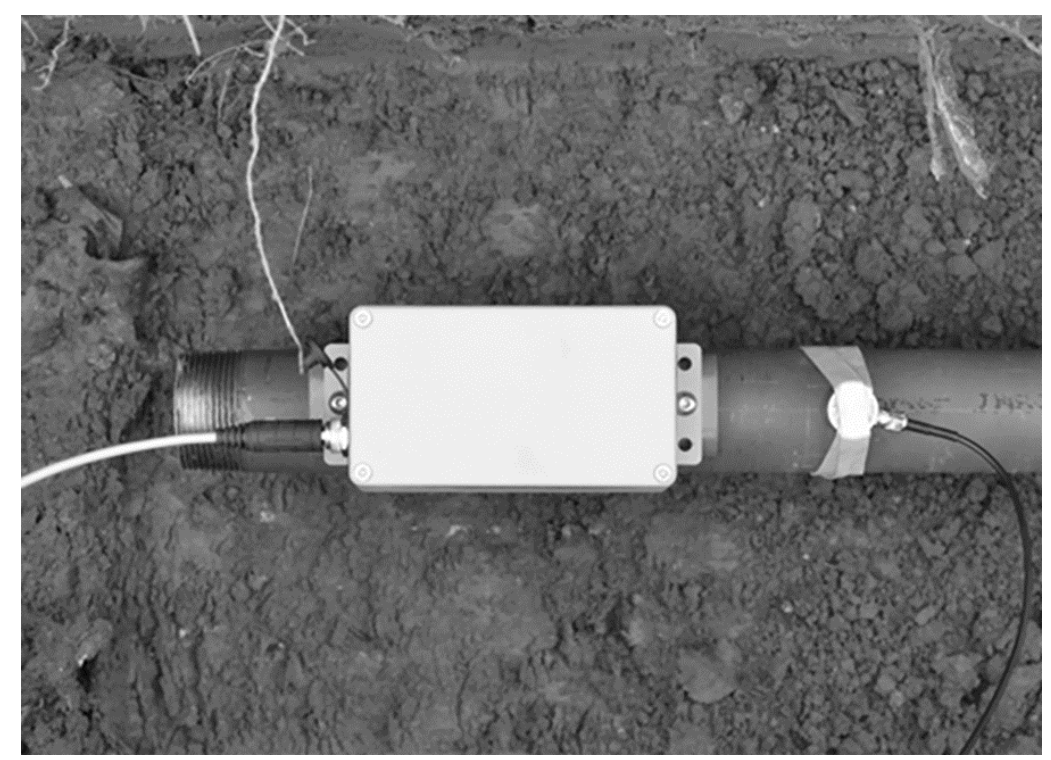

Figure 9. Photograph of the source generator and a transducer coupled to the pipe
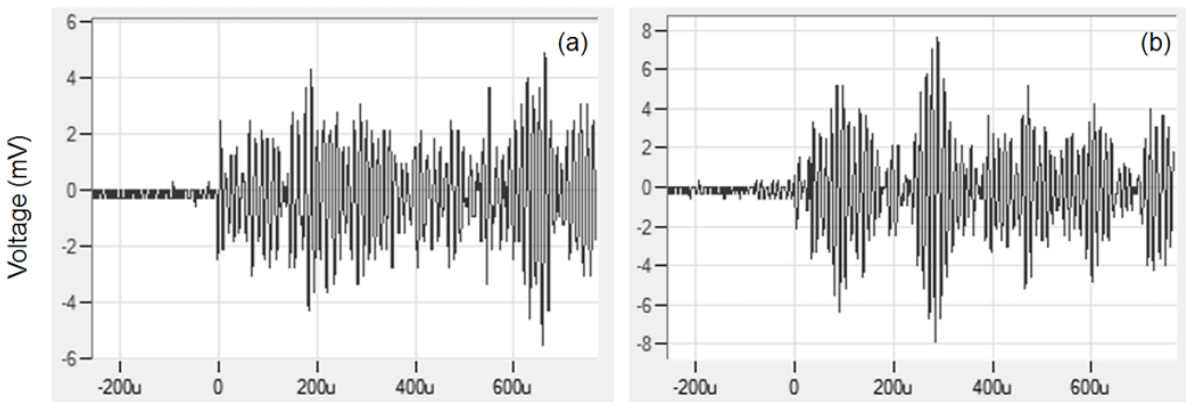

Time $(\mu \mathrm{s})$

Figure 10. Typical AE waveforms produced by the source generator 


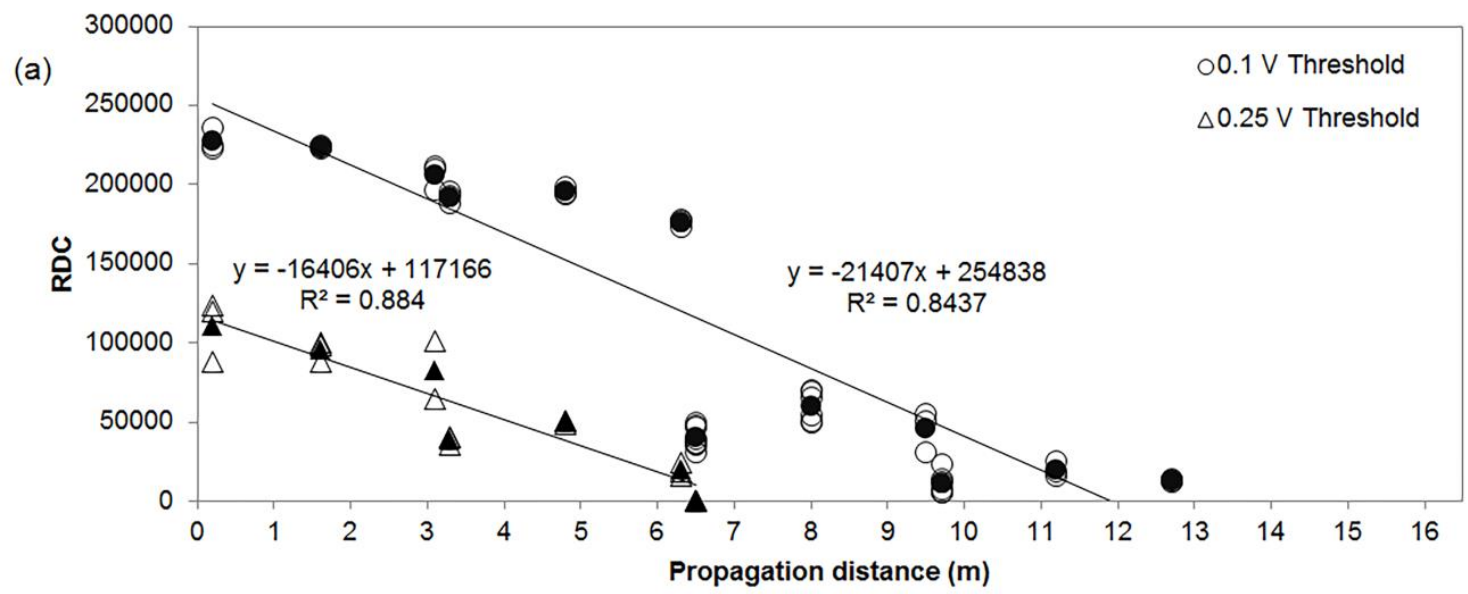

(b)

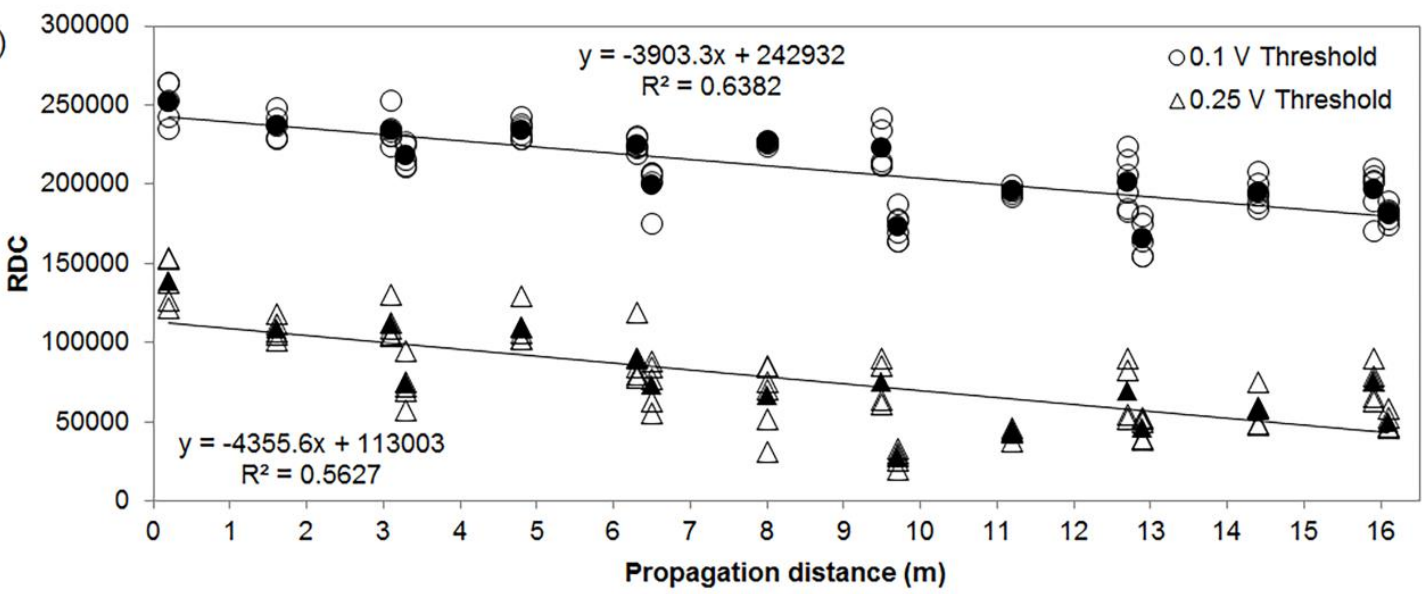

Figure 11. Results of RDC (induced by source generator over 10 second durations) vs. propagation distance from the air-pipe-air tri-layer system; a) loose couplings, b) tight couplings

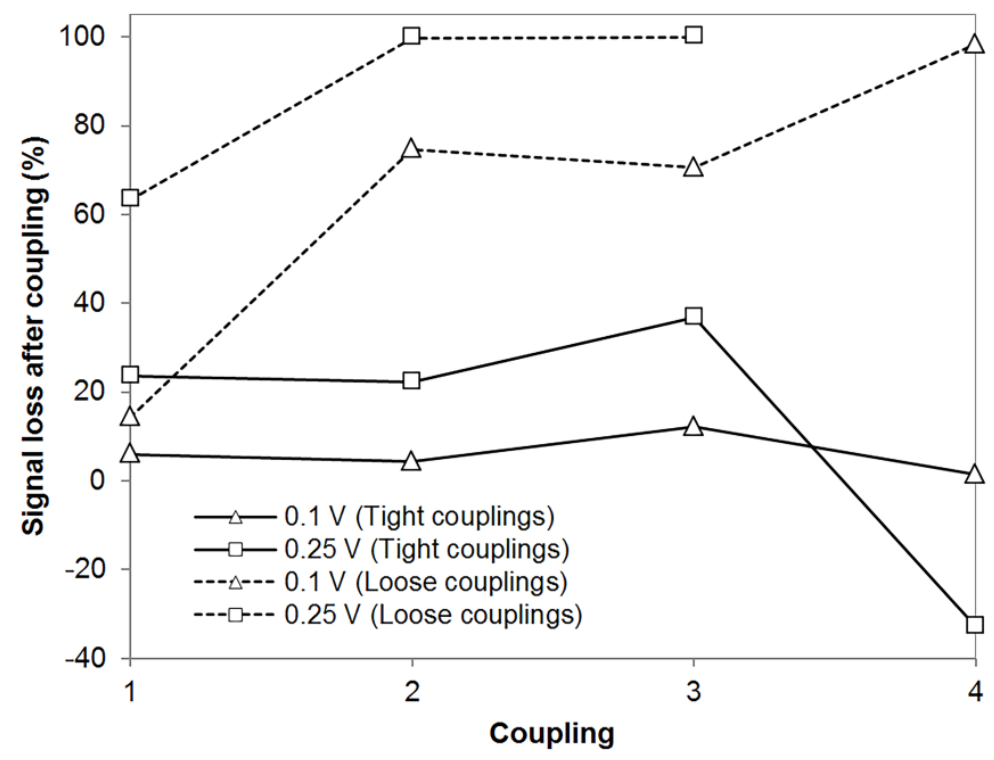

Figure 12. Percentage signal loss over each coupling from the air-pipe-air tri-layer system experimentation 

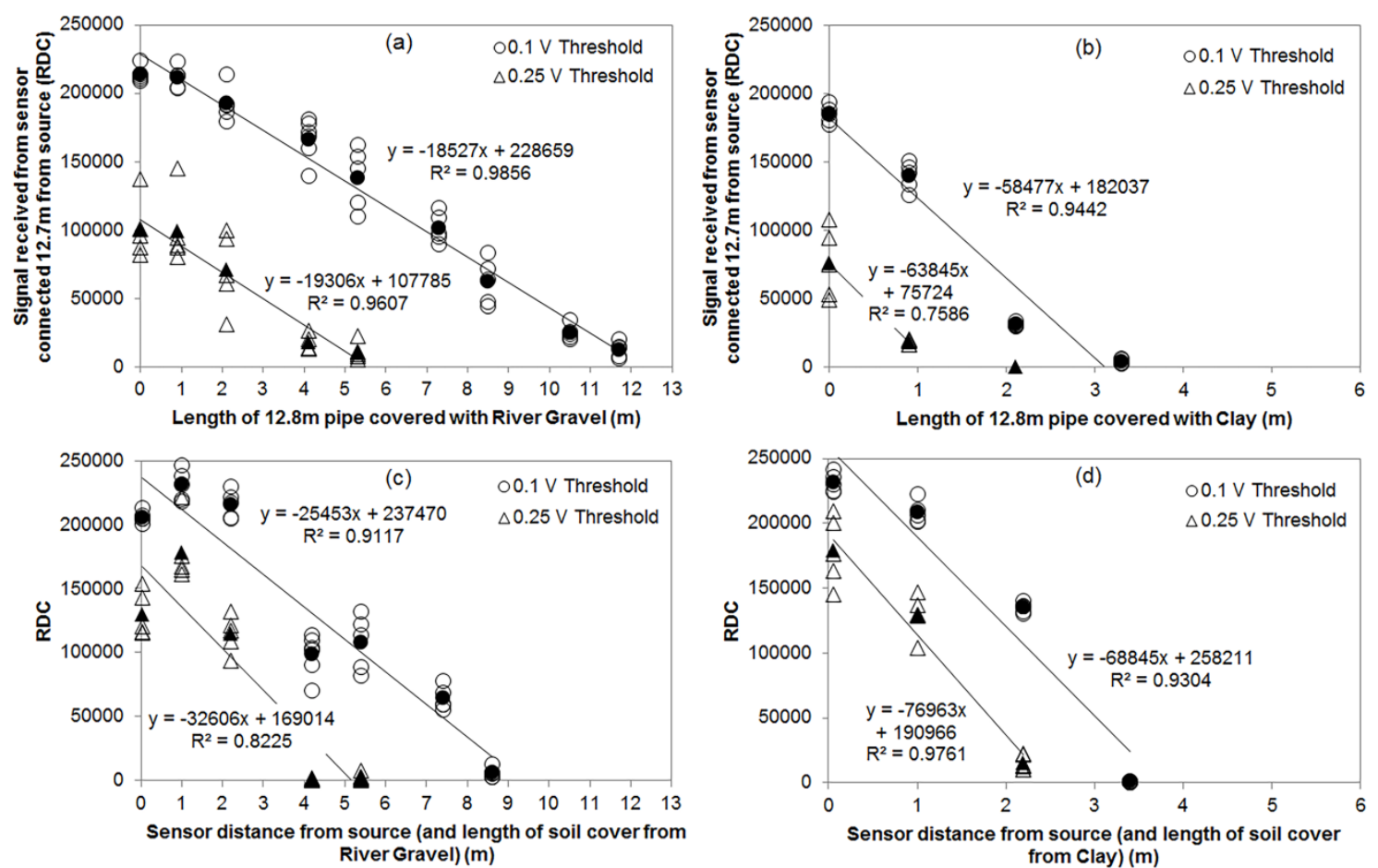

Figure 13. Results of RDC (induced by source generator over 10 second durations) vs. propagation distance from the air-pipe-soil tri-layer systems: a) AE measured by end sensor for River Gravel cover, b) AE measured by end sensor for Clay cover, c) AE measured by running sensor for River Gravel cover, d) AE measured by running sensor for Clay cover

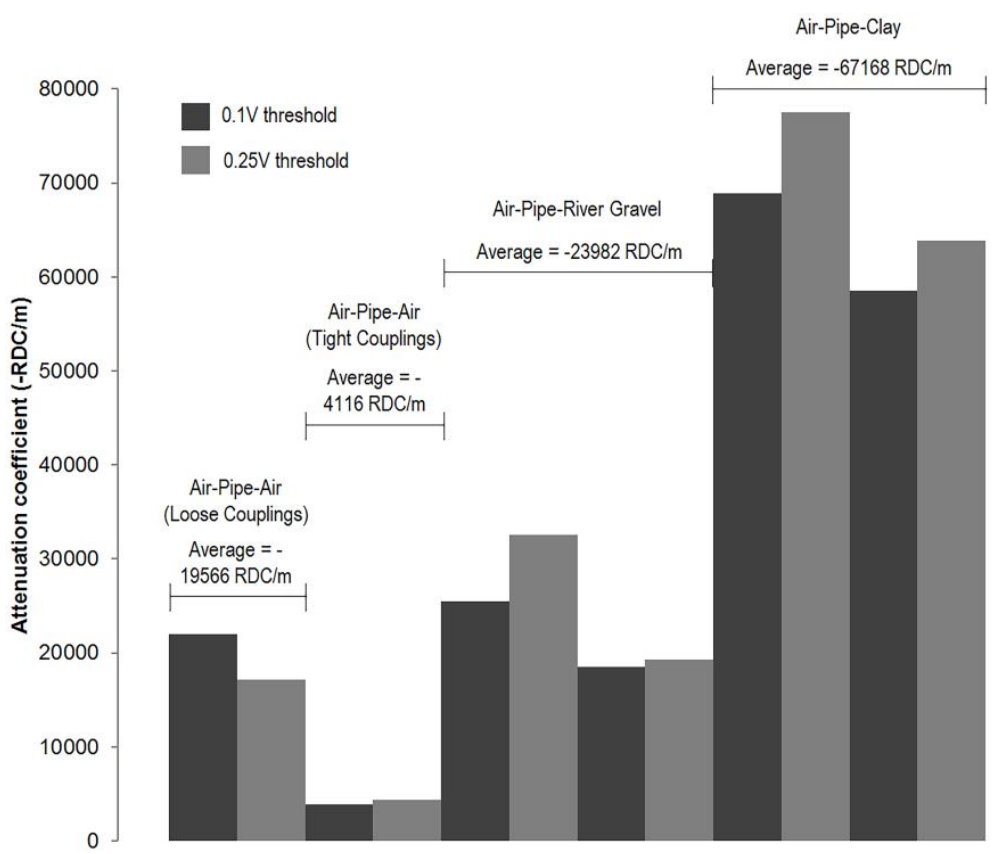

Figure 14. Attenuation coefficients in RDC per metre derived for each of the tri-layer systems (including losses due to couplings) 


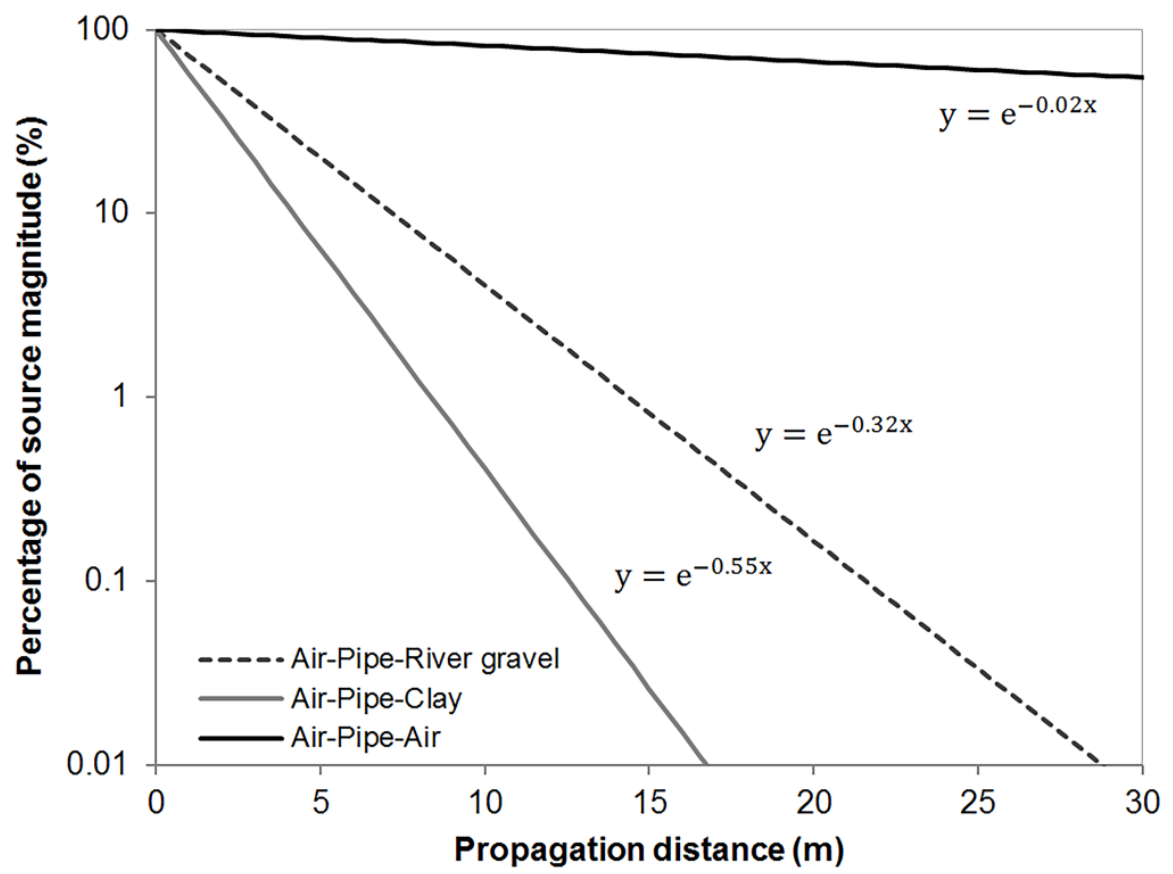

Figure 15. Percentage of source magnitude vs. propagation distance relationship derived using the attenuation coefficients for each tri-layer system with tight couplings (including coupling losses)

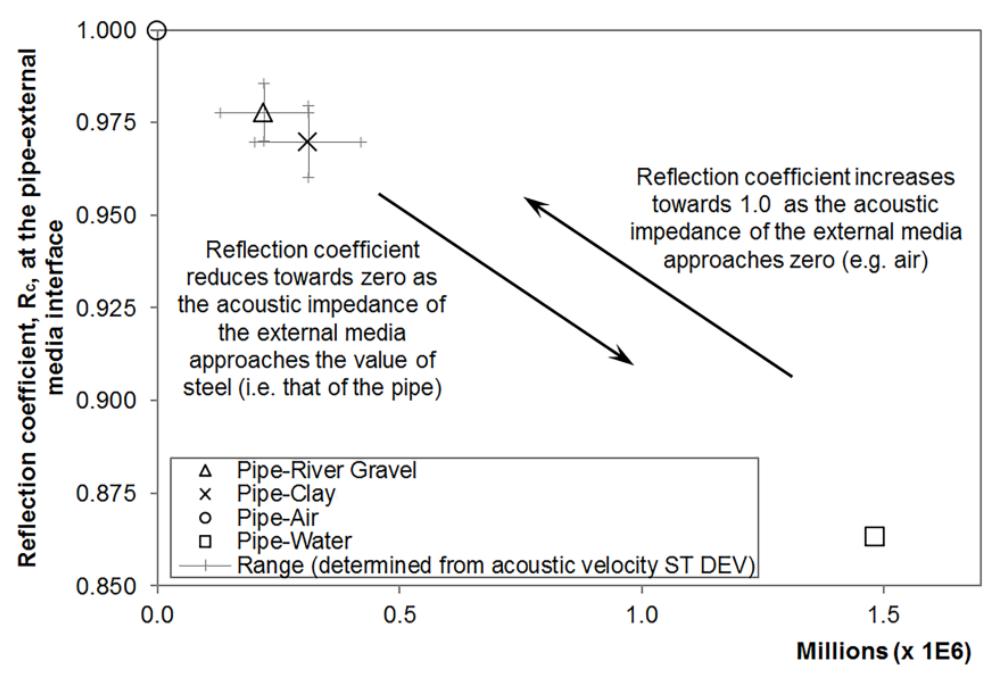

Acoustic Impedance, $\mathbf{Z}\left(\mathbf{k g} / \mathbf{m}^{2} \mathbf{s}\right)$, of external media

Figure 16. Reflection coefficient (at the pipe-external media interface) vs. acoustic impedance of the external media (for the media studied) 


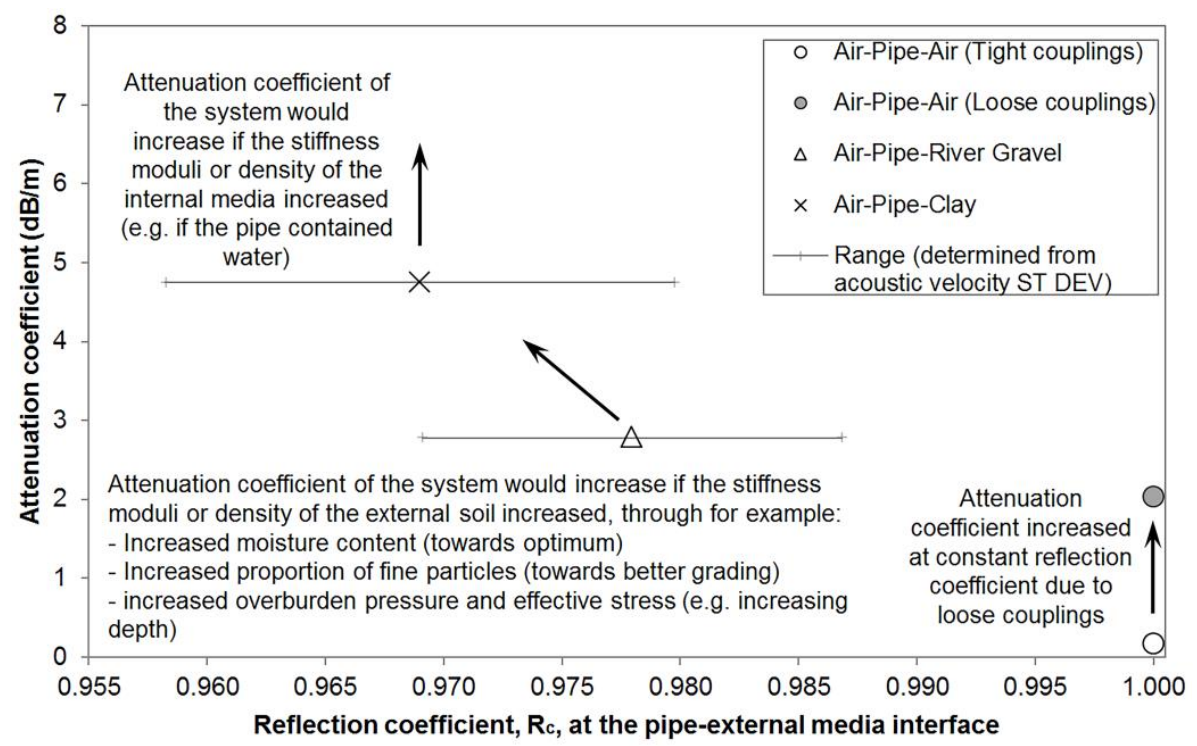

Figure 17. Attenuation coefficient vs. reflection coefficient (at the pipe-external media interface) for the tri-layer systems studied (i.e. steel pipe with screw threaded couplings and air as an internal environment) at a monitoring frequency of 20 to $30 \mathrm{kHz}$

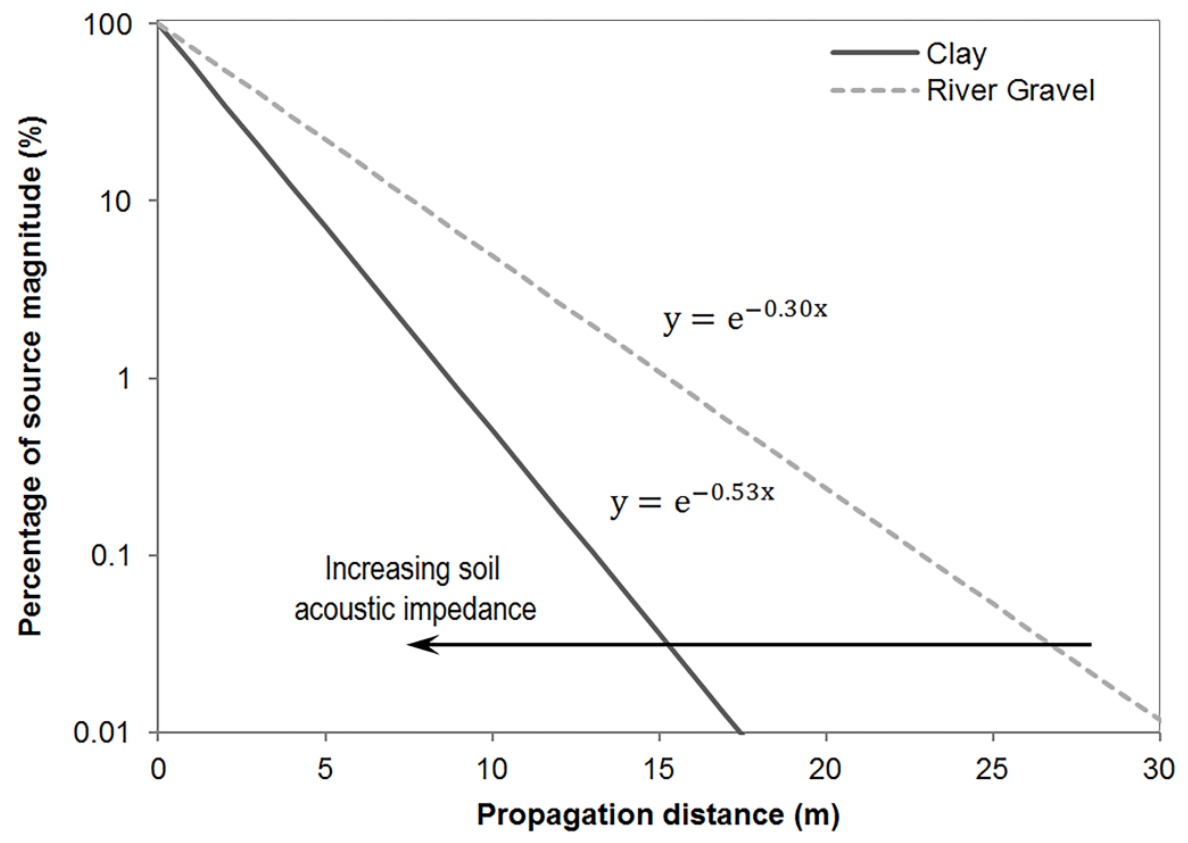

Figure 18. Percentage of source magnitude vs. propagation distance relationships for boundary losses due to soil cover (soil cover losses) for the soils examined, demonstrating that soil cover loss varies proportionally with the soil's acoustic impedance 